\title{
The $\Delta$ F508-CFTR mutation inhibits wild-type CFTR processing and function when co-expressed in human airway epithelia and in mouse nasal mucosa
}

Torry A Tucker ${ }^{1,2,4}$, James A Fortenberry ${ }^{2}$, Akos Zsembery ${ }^{1,2,3}$, Lisa M Schwiebert ${ }^{1,2^{*}}$ and Erik M Schwiebert ${ }^{1,2,5^{*}}$

\begin{abstract}
Background: Rescue or correction of CFTR function in native epithelia is the ultimate goal of CF therapeutics development. Wild-type (WT) CFTR introduction and replacement is also of particular interest. Such therapies may be complicated by possible CFTR self-assembly into an oligomer or multimer.

Results: Surprisingly, functional CFTR assays in native airway epithelia showed that the most common CFTR mutant, $\Delta$ F508-CFTR ( $\Delta$ F-CFTR), inhibits WT-CFTR when both forms are co-expressed. To examine more mechanistically, both forms of CFTR were transfected transiently in varying amounts into IB3-1 CF human airway epithelial cells and HEK-293 human embryonic kidney cells null for endogenous CFTR protein expression. Increasing amounts of $\triangle$ F-CFTR inhibited WT-CFTR protein processing and function in CF human airway epithelial cells but not in heterologous HEK-293 cells. Stably expressed $\Delta F$-CFTR in clones of the non-CF human airway epithelial cell line, CALU-3, also showed reduction in CAMP-stimulated anion secretion and in WT-CFTR processing. An ultimate test of this dominant negative-like effect of $\Delta$ F-CFTR on WT-CFTR was the parallel study of two different CF mouse models: the $\Delta$ F-CFTR mouse and the bitransgenic CFTR mouse corrected in the gut but null in the lung and airways. WT/ $\Delta \mathrm{F}$ heterozygotes had an intermediate phenotype with regard to CFTR agonist responses in in vivo nasal potential difference (NPD) recordings and in Ussing chamber recordings of short-circuit current (ISC) in vitro on primary tracheal epithelial cells isolated from the same mice. In contrast, CFTR bitransgenic +/- heterozygotes had no difference in their responses versus +/+ wild-type mice.
\end{abstract}

Conclusions: Taken altogether, these data suggest that $\triangle F-C F T R$ and WT-CFTR co-assemble into an oligomeric macromolecular complex in native epithelia and share protein processing machinery and regulation at the level of the endoplasmic reticulum (ER). As a consequence, $\Delta$ F-CFTR slows WT-CFTR protein processing and limits its expression and function in the apical membrane of native airway epithelia. Implications of these data for the relative health of CF heterozygous carriers, for CFTR protein processing in native airway epithelia, and for the relative efficacy of different CF therapeutic approaches is significant and is discussed.

Keywords: Cystic fibrosis (CF), CFTR, Biogenesis, CF heterozygote, Oligomer, Chloride ion channels

\footnotetext{
*Correspondence: Ischwieb@uab.edu; erik@discoverybiomed.com

'Departments of Cell Developmental and Integrative Biology, University of Alabama at Birmingham, 1918 University Blvd, Birmingham, AL 35294-0005, USA

${ }^{2}$ Gregory Fleming James Cystic Fibrosis (CF) Research Center, University of Alabama at Birmingham, 1918 University Blvd, Birmingham 35294-0005AL, USA

Full list of author information is available at the end of the article
} 


\section{Background}

$\mathrm{CF}$ is a monogenic disorder, a rare misfolded protein disorder, and the most common autosomal recessive genetic disease found in the Caucasian population [1-3]. CF is caused by mutations in CFTR that lead to reduced surface expression and/or function of this cyclic AMPregulated chloride $\left(\mathrm{Cl}^{-}\right)$channel among other airway, gastrointestinal and other epithelial tissue defects [1-4]. The most commonly occurring CF mutation is the $\triangle$ F508-CFTR ( $\triangle$ F-CFTR) mutation that occurs in approximately $70-90 \%$ of the CF population worldwide [1-4]. This mutation causes a folding defect in the CFTR protein that causes ER retention of the majority of the $\triangle$ F-CFTR protein [1-6].

CF disease phenotype correlates better with CFTR genotype in the gastrointestinal (GI) tract, where secretion of pancreatic enzymes and bile along with salt, bicarbonate, and water is essential for function [4]. However, in the CF lung and airways, there is little correlation between CFTR genotype and lung and airways disease phenotype [4]. One $\triangle$ F-CFTR homozygous patient can have severe disease and another $\triangle \mathrm{F}$-CFTR homozygous patient can present a more mild disease; this is the rationale for $\mathrm{CF}$ siblings and twins genotype/phenotype correlation studies currently in progress $[7,8]$. This lack of correlation may be explained by: (a) secondary or modifier genes that protect or fail to protect an individual from CF lung and airways disease progression [7]; (b) additional genes that cause predisposition to CF lung and airways disease progression $[7,8]$; and/or (c) CFTR's known role as a regulator of other conductances and cellular processes [4]. Better understanding of $\triangle \mathrm{F}$-CFTR biology, physiology and lung and airways defects is critical, because the majority of the associated pathology and corresponding mortality of $\mathrm{CF}$ occurs in the pulmonary system.

One of the hypothesized and more viable methods to treat $\mathrm{CF}$ is by gene correction or protein replacement $[9,10]$. The goal is to introduce or replace the defective copy of CFTR with a functional wild-type (WT) copy that could generate a normal mRNA and a functional protein. Promising methods of introducing the WT-CFTR gene is via lipid- or virallymediated transduction $[9,10]$. Barriers to these methods are currently being overcome $[9,10]$. One overwhelming problem is the lack of an animal model that displays the characteristic lung pathology seen in humans that a gene-bearing vector seeks to correct $[9,10]$; however, recent work on porcine and ferret animal models of CF is promising [11-13]. Work described herein introduces another concept that needs to be addressed in the context of these putative therapies: What if the mutant CFTR protein interacts with and affects the processing and function of the introduced WTCFTR? A dominant negative-like effect of the endogenous $\triangle$ F-CFTR could also limit the effect of a WT-CFTR gene or protein correction or a CF corrector drug in a target cell.
Recent work has focused on examination of WTCFTR and mutant CFTR biogenesis, trafficking, and functions within CFTR's native environment, the polarized airway epithelial cell. In this light, we published important methods on transient transfection of CFTR into non-polarized and polarized epithelial cells [14]. We also showed that WT-CFTR processing in epithelial cells is more efficient than first suggested in heterologous cell systems over-expressing CFTR [15]. In the context of this work, we observed curious results that led us to test the hypothesis that mutant forms of CFTR can interact with and inhibit WT-CFTR function in airway epithelial cells. We present results herein with in vivo and in vitro approaches that support the hypothesis that $\triangle \mathrm{F}-\mathrm{CFTR}$ inhibits WT-CFTR in a dominant negative-like manner when co-expressed together in the same epithelium.

This hypothesis is germane to two different fields of $\mathrm{CF}$ research. The former relates to whether defects or predispositions to dysfunction are found in the CF heterozygous carrier. The latter involves whether or not CFTR exists within an oligomeric protein complex in epithelial cells as a monomer or a multimer. Throughout the clinical study of endpoints in CF, partial defects or dysfunction in the CF heterozygous carrier have been observed. However, because the CF carrier does not present with full progressive CF disease in the GI tract or in the lung and airways and because genotypes were not fully defined in these older studies, CF carriers have not be studied deeply or as a full study group compared to homozygotes or WT controls. Heterozygous cell models are also not available for similar reasons. However, partial loss in the volume of sweat or in rate of secretion in response to agonists has been documented in CF heterozygotes versus WT controls [16,17], whereas CF homozygotes fail to respond to agonists. Graded differences in sweat $\left[\mathrm{Cl}^{-}\right]$amounts were observed that yielded three statistically different groups in a continuum between CF homozygote patients, CF heterozygote carriers, and WT controls. Clinical endpoints have noted statistically valid predispositions to pancreatitis, rhinitis and sinusitis, allergic bronchopulmonary aspergillosis, and airway hyper reactivity in CF heterozygotes [18-21]. The latter predisposition to airway reactivity has been studied for several decades and have driven asthma geneticists to document prevalence of CF gene mutations in populations with severe asthma prevalence [18]. Additional studies were found in our literature review, but only the subset cited above studied all three genotypes. Nevertheless, the listed observations above provided a compelling rationale for studying wild-type CFTR and mutant CFTR interaction as a possible cause of heterozygote dysfunction.

A multitude of studies focusing on CFTR protein biochemistry have concluded that CFTR is a monomer 
[22-26]. However, this conclusion was supported by work largely performed in heterologous cell over-expression systems and was arrived at before the identification of CFTR binding partners at the $\mathrm{N}$ - and C-termini [27-34]. In particular, the identification of the PDZ-binding motif on the extreme C-terminal end of the carboxy-terminal tail and epithelial PDZ binding proteins such as EBP-50 (NHERF-1), E3-KARP (NHERF-2), CAP-70, and CAL among others have made many investigators re-think this conclusion [35-41]. This is particularly true in the context of the epithelial cell, where a single CFTR monomer could associate with a second CFTR monomer or with a larger number of CFTR monomers via PDZ-dependent contacts. Several investigators have shown that association with PDZ binding proteins affect CFTR $\mathrm{Cl}^{-}$channel function, trafficking and localization [36-41]. Bear and colleagues have recently assessed the monomer versus multimer issue with CFTR expressed in different cell models and subjected the CFTR-enriched lysates to sucrose gradient analysis under non-denaturing and denaturing conditions [22]. Their conclusion was that CFTR existed as a monomer, as a dimer, and, possibly, in higher order multimers, but that a monomer was sufficient for $\mathrm{Cl}^{-}$channel activity. Moreover, Naren and colleagues have shown in heterologous and epithelial cells that CFTR is a multimer that self-associates by a mechanism that does not appear to involve the PDZ motif in the C-terminus [23]. In addition, Cormet-Boyaka et al. characterized a trans-complementation mechanism where fragments of CFTR could rescue CFTR folding mutations [33]. They state that masking the mutated region of the CFTR polypeptide with a corresponding WT fragment could cause the mutant to escape the ER [32,33]. Zerhusen et al. showed that a CFTR concatemer acted in a similar manner to a single CFTR protein, arguing for possible cooperation of multiple CFTR proteins to form a functional channel [27]. In their discussion, these authors hint at the idea that mutant CFTR proteins could affect WT-CFTR [22,23,27,32,33]. The same has been studied recently for mdr P-glycoproteins, where monomeric and multimeric conclusions have been drawn [28]. Therefore, it is still an open question whether CFTR assembles as a multimer through: (a) selfassociation; (b) as an oligomeric complex; or (c) resides as a multimer within an oligomer. Nevertheless, there are compelling data from our laboratory and from others that multiple CFTR polypeptides can interact by either or both mechanisms in epithelial cells.

In the study herein, our data address both issues of heterozygote dysfunction and CFTR multimerization by assessing the dominant negative-like inhibition of WTCFTR by $\triangle$ F-CFTR in human airway epithelial cells. Critically, the effect is specific to the $\triangle$ F-CFTR mutant. The results also speak to the need to overcome mutant CFTR effects on WT-CFTR introduced by emerging therapeutic methods. We show that $\triangle \mathrm{F}-\mathrm{CFTR}$, when coexpressed with wild-type CFTR by multiple methods, inhibits WT-CFTR processing and, therefore, function in epithelial cells but not in heterologous cells.

\section{Methods and materials \\ Cell culture}

All cell culture substrates (plates, flasks, and filters supports) for epithelial cells were coated with 1:15 diluted Vitrogen 100 solution in Ca/Mg Free Dulbecco's PBS (Life Technologies/Invitrogen). The diluted Vitrogen solution is added, allowed 2-3 min to coat the substrate, and is then removed for air drying in a sterile hood. CALU-3 (a human non-CF submucosal airway serous cell line endogenously expressing CFTR) [42] and HEK293T (a human embryonic kidney heterologous cell model over-expressing the large $\mathrm{T}$ antigen to amplify cDNA expression) [43] were grown in Minimal Essential Medium (MEM) with $10 \%$ heatinactivated fetal bovine serum (Life Technologies/Invitrogen), $6 \mathrm{ml}$ of penicillin-streptomycin $100 \times$ solution (penicillin $100 \mathrm{U} / \mathrm{ml}$ and streptomycin $100 \mu \mathrm{g} / \mathrm{mg}$ final; Life Technologies/Invitrogen), $6 \mathrm{ml}$ of $200 \mathrm{mM} \mathrm{L}$-glutamine 100X solution (2 mM Final; Life Technologies/Invitrogen), and $2 \mathrm{ml}$ of fungizone solution (amphotericin B, $1 \mathrm{ug} / \mathrm{ml}$ final; Life Technologies/Invitrogen). The IB3-1 cell line (derived from a CF human bronchus expressing the $\triangle \mathrm{F} 508$ and W1282X mutant forms of CFTR) was grown in LHC-8 media without gentamycin (Biofluids) supplemented with $5 \%$ heat-inactivated fetal bovine serum, $6 \mathrm{ml}$ of penicillin-streptomycin 100x solution (penicillin $100 \mathrm{U} / \mathrm{ml}$ and streptomycin $100 \mu \mathrm{g} / \mathrm{mg}$ final), $6 \mathrm{ml}$ of $200 \mathrm{mM}$ L-glutamine 100X solution (2 mM final), and $2 \mathrm{ml}$ of fungizone solution (amphotericin B, $1 \mathrm{ug} / \mathrm{ml}$ final).

\section{Culture of polarized epithelial cell monolayers}

CALU-3 non-CF human epithelial cells (parental, G418resistant lacking mutant CFTR, and G418-resistant expressing mutant CFTR; see selection procedure below) were seeded onto coated $6.5 \mathrm{~mm}$ diameter polyester Transwell Filters (Corning-Costar, Corning, NY) at $1 \times 10^{6}$ cells per insert. For these cell monolayers, a measured transepithelial electrical resistance $\left(R_{T E}\right)$ of $>2,000 \Omega \cdot \mathrm{cm}^{2}$ was achieved routinely and sufficient to perform the subsequent Ussing Chamber transepithelial $\mathrm{Cl}^{-}$secretion assays.

\section{Transient transfection of non-polarized epithelial cells}

These methods have been published previously [14]. However, co-transfection of wild-type and mutant CFTR cDNAs was a novel feature of this study to simulate a "heterozygous" cell. The methods of LipofectAMINE PLUS-mediated transient transfection were similar; however, the DNA combinations were varied in the following 
manner for a typical experiment presented below for cells grown in a $10 \mathrm{~cm}$ diameter coated culture plate:

- EV or Empty Vector $=6.75 \mu \mathrm{g}$ of pcDNA 3.1 plasmid DNA devoid of CFTR cDNA

- WT-CFTR-bearing Vector $=0.75 \mu$ g (Balance "backfilled" with $6 \mu \mathrm{g}$ of empty vector or EV)

- $\triangle \mathrm{F}$-CFTR-bearing Vector $=0.75 \mu \mathrm{g}$ (Balance "backfilled" with $6 \mu \mathrm{g}$ of EV).

Note below that the amount of $\triangle \mathrm{F}$-CFTR was increased in a titration to determine how much $\triangle \mathrm{F}$-CFTR vector needed to be transfected to make $\Delta$ F-CFTR protein that was equivalent to WT-CFTR because of the dramatically reduced protein half-life of this ER retention mutant $[44,45]$. Thus, in other transiently transfected cultures, a mixture of WT-CFTR and $\triangle$ F-CFTR-bearing vector was co-expressed in the same cells in the following mixtures:

- $1 \times$ WT with $1 \times \Delta \mathrm{F}=0.75 \mu \mathrm{g}$ WT, $0.75 \mu \mathrm{g} \Delta \mathrm{F}, 5.25 \mu \mathrm{g}$ EV

- $1 \times \mathrm{WT}$ with $2 \times \Delta \mathrm{F}=0.75 \mu \mathrm{g}$ WT, $1.5 \mu \mathrm{g} \Delta \mathrm{F}, 4.5 \mu \mathrm{g}$ EV

- $1 \times$ WT with $4 \times \Delta \mathrm{F}=0.75 \mu \mathrm{g}$ WT, $3.0 \mu \mathrm{g} \Delta \mathrm{F}, 3.0 \mu \mathrm{g}$ EV

- $1 \times \mathrm{WT}$ with $8 \times \Delta \mathrm{F}=0.75 \mu \mathrm{g} \mathrm{WT}, 6.0 \mu \mathrm{g} \Delta \mathrm{F} ; 0 \mu \mathrm{g} \mathrm{EV}$

These ratios were used for the IB3-1 CF and HEK-293 T cells transfected transiently. For G551D-CFTR experiments, the same amounts of G551D-CFTR bearing plasmid were used as a substitute for $\triangle$ F-CFTR. These DNA combinations were incubated with PLUS reagent in OptiMEM-1 serum-free medium for $15 \mathrm{~min}$ at room temperature. After the first incubation, LipofectAMINE reagent from a separate tube was mixed with the PLUS reagent-primed plasmid DNA combinations. The complete transfection cocktail was incubated for another $15 \mathrm{~min}$ at room temperature. During the incubation periods, the cells were washed 3X with Opti-MEM-1 medium to remove all serum and to sensitize the cells to the serum-free medium. After the final wash, the transfection cocktail was brought up to a final volume of $6 \mathrm{mls}$ from a mixing volume of $1 \mathrm{ml}$. The cells were then incubated for $6 \mathrm{~h}$ at $37^{\circ} \mathrm{C}$ in the humified $\mathrm{CO}_{2}$ incubator. After the 6-h incubation, the cells were washed $2 \times$ with Opti-MEM and $1 \times$ with FBS containing media to remove excess lipidDNA complexes. The cells were re-fed $24 \mathrm{~h}$ after transfection and studied for CFTR biochemistry and function $48 \mathrm{~h}$ post-transfection.

\section{Transient transfection of HEK293T heterologous cells}

Similar methods were followed to those described above with the notable exception that Effectene reagent (Qiagen) was used for HEK293T cells [14]. This reagent was found to be toxic to all epithelial cell models but ideal for HEK-293 cells [14]. Surprisingly, there was minimal toxicity to HEK-293 cells while a transfection efficiency of 90-95\% was routine. Enhancer reagent was added to OptiMEM-1 medium along with the same DNA combinations above. The mixture was incubated for $10 \mathrm{~min}$ at room temperature. After the initial incubation, $24 \mu \mathrm{l}$ of Effectene reagent was added to each tube, followed by $10 \mathrm{~min}$ incubation at room temperature. During the incubations, the cells are washed $3 \times$ with Opti-MEM. After the final wash, all media is removed from the cells, and transfection cocktails are brought up to a $6 \mathrm{ml}$ volume and added to the culture dishes. The cells were incubated in transfection cocktail for $4 \mathrm{~h}$ at $37^{\circ} \mathrm{C}$ in the humified $\mathrm{CO}_{2}$ incubator. After the 4-h incubation, the cells were washed $2 \times$ with Opti-MEM and $1 \times$ with FBS containing media. The cells were re-fed $24 \mathrm{~h}$ after transfection and studied for CFTR biochemistry and function $48 \mathrm{~h}$ post-transfection.

\section{Stable transfection and selection of "heterozygous" cells} Similar LipofectAMINE PLUS-based methods were used as above. Vector bearing $\triangle$ F508-CFTR cDNA was transiently transfected in combination with the pcDNA 3.1 vector with a G418-resistance gene cassette to confer antibiotic resistance into the non-CF airway epithelial cell lines, CALU-3. CALU-3 cells grow as 'islands' of cells that eventually grow and fuse together as a confluent monolayer. The cells were transfected as small islands dispersed throughout the culture dish. The cells were re-fed $24 \mathrm{~h}$ after transfection and cultures were allowed to grow until the islands grew much larger but were still not yet fused together as a confluent culture. After 7-10 days of culture as described above, MEM complete media was added that was also supplemented with $700 \mu \mathrm{g} / \mathrm{ml}$ of genetic in (G418) to select stably transfected CALU-3 cell islands. The cells were washed with PBS and fed G418-containing MEM complete medium every other day that was made fresh and filtered to keep G418 activity high in the cultures. The majority of the cell islands died; however, some cells within islands lived and began to form isolated colonies. These 'island colonies' were then selected using cloning rings (the reason for using $10 \mathrm{~cm}$ diameter dishes was that sterile cloning rings could be inserted by simply lifting the lid of the dish). The cloning rings were dipped in sterile, autoclaved vasoline gel to allow them to adhere to the bottom of the plate. Once these colonies grew to confluence within the cloning ring, the clonal island colony' was transferred to a 24 well plate for further expansion. They were then expanded further into flasks as well as frozen in micro-aliquots to have the earliest possible passage following selection cryopreserved. 


\section{Immunoprecipitation and phospholabeling of CFTR}

Published methods were followed [15]. Cells were washed $1 \mathrm{X}$ with $\mathrm{CaMg}$ containing PBS. The cells were kept at $4^{\circ} \mathrm{C}$ during washes. The cells were subsequently lysed in "Radioimmunopreciptiation Assay" (RIPA) Buffer containing NP40 (1\%), sodium deoxycholate (.5\%), SDS (0.1\% at $\mathrm{pH}$ 8.0), and sodium chloride (150 mM) supplemented with Protease Inhibitor Cocktail (Roche). Samples were homogenized and incubated for $30 \mathrm{~min}$ at $4^{\circ} \mathrm{C}$. The lysates were then centrifuged at $14,000 \mathrm{~g}$ at $4^{\circ} \mathrm{C}$ for $20 \mathrm{~min}$. The supernatants were then collected and protein concentrations calculated using the BCA Protein Assay Kit and a microplate reader. Immunoprecipitations were performed using Protein A Agarose and the anti-CFTR Ab targeted to the NBD-1/R region of CFTR (Bedwell/Collawn) with at least $800 \mathrm{ng}$ of lysate supernatant. The supernatants were added to the $\mathrm{Ab} /$ Protein Agarose Solution and allowed to incubate at $4^{\circ} \mathrm{C}$ for $2 \mathrm{~h}$ or overnight on an endover-end shaker (rotator). Samples were then centrifuged at $14,000 \mathrm{~g}$ for $2 \mathrm{~min}$ and the supernatant removed from the pelleted agarose beads. RIPA buffer $(750 \mu \mathrm{l})$ was then added to the beads, centrifuged for $2 \mathrm{~min}$ at 14,000 g, and the supernatant removed. This was repeated 2 times. On the final wash, the pelleted beads were washed with $750 \mu \mathrm{l}$ PKA Buffer. Two $\mu \mathrm{l}$ of PKA catalytic subunit and $10 \mu \mathrm{l}$ $\left[\gamma^{-}{ }^{32} \mathrm{P}\right]$ ATP were added to phosphorylate the bound CFTR to make it detectable with phosphor-imaging technology. The samples were then allowed to incubate for $45 \mathrm{~min}$ at $30^{\circ} \mathrm{C}$. After the incubation, the cells were washed $3 \mathrm{X}$ with RIPA buffer at room temperature. Excess RIPA buffer was then removed from the beads. Thirty-five $\mu \mathrm{l}$ of $2 \mathrm{X}$ sample buffer with $\beta$-mercaptoethanol was added to the samples and incubated at $37^{\circ} \mathrm{C}$ for $15 \mathrm{~min}$. Samples were then run on a $6 \%$ Tris Agarose gel at $150 \mathrm{~V}$ for $90 \mathrm{~min}$, dried in a gel dryer, and analyzed on the PhosphorImager.

\section{Voltohmeter open-circuit and ussing chamber short- circuit current measurements of monolayer electrical properties}

$\mathrm{R}_{\mathrm{TE}}$ was measured using the Millipore MilliCell ERS Voltohmeter that uses $\mathrm{Ag}$ - $\mathrm{AgCl}$ pelleted chopstick electrodes. The $\mathrm{R}_{\mathrm{TE}}$ was monitored on a daily basis and was used as an indicator of the level of maturity of the monolayer. When monolayers had matured and reached a $R_{\mathrm{TE}}$ plateau (> 1,000-2,000 Ohms), Ussing chamber recordings of the short-circuit currents were performed. Ussing chamber experiments were performed as described previously [46]; however, they were designed to activate and monitor CFTR $\mathrm{Cl}^{-}$currents in accordance with recent published studies. Recordings were performed in OptiMEM-1 reduced serum medium or in Ringers enriched with bicarbonate on CALU-3 non-CF airway epithelial cells grown as monolayers (a submucosal gland serous cell model with abundant endogenous
CFTR expression) that were or were not stably transduced with $\Delta$ F508-CFTR. Amiloride $(10 \mu \mathrm{M})$ was added to the apical solution to inhibit any residual $\mathrm{ENaC}$ mediated $\mathrm{Na}^{+}$currents which were negligible in these cell models grown under these conditions. Then, forskolin $(2 \mu \mathrm{M})$ was added to both sides of the cell monolayers to increase cyclic AMP and stimulate CFTR $\mathrm{Cl}^{-}$conductance. To maximally activate CFTR $\mathrm{Cl}^{-}$conductance in these monolayers, genistein $(50 \mu \mathrm{M})$ was added to both sides of the monolayer. In some experiments, glibenclamide (glyburide, $50 \mu \mathrm{M}$ ) was added to inhibit the CFTR-mediated $\mathrm{Cl}^{-}$conductance (data not shown). Magnitude of the forskolin- and genistein-activated $\mathrm{Cl}^{-}$ conductance was compared statistically between parental or G418-resistant clones CALU-3 cells that lacked $\triangle$ F508-CFTR versus those that possessed $\triangle$ F508-CFTR.

\section{SPQ halide fluorescence assay of halide transport}

The SPQ assay was used to detect the amount of active CFTR $\mathrm{Cl}^{-}$channels that are functional at the plasma membrane of the transiently transfected cells. It has been used previously by our laboratory in published papers [47]. The SPQ fluorescent dye is sensitive to halides, some of which quench the dye's fluorescence (iodide, chloride) and some of which do not (nitrate). The cells are seeded onto a glass coverslip. After a $24 \mathrm{~h}$ period, the cells were then transiently transfected with the CFTR cDNAs. Twenty-four hours after initiation of transfection, the cells were placed in media containing the SPQ dye $(10 \mathrm{mg} / \mathrm{ml})$ for overnight incubation. After another $24 \mathrm{~h}$, the cover slips were taken and placed on the fluorescence scope (the cover slips actually form the bottom of the flow chamber). Twenty-five to 30 individual cells were selected based upon the intensity of their fluorescence, which denotes the efficiency of SPQ dye uptake. Their fluorescence is then measured and recorded. The SPQ fluorescence protocol is as follows. The cells were placed in the perfusion chamber and exposed to 3 different buffers: (1) NaI buffer (iodide enters the cells and quenches SPQ fluorescence; (2) $\mathrm{NaNO}_{3}$ buffer (nitrate reverses this gradient and allows the iodide to passively diffuse out of the cells and unquenches the fluorescence); (3) $\mathrm{NaNO}_{3}$ buffer with a cAMP agonist cocktail (100 $\mu \mathrm{M}$ isobutylmethylxanthine (IBMX), $10 \mu \mathrm{M}$ forskolin, and $200 \mu \mathrm{M}$ dibutyryl-cAMP, 8-bromo-cAMP or CPT-CAMP) to stimulate CFTR $\mathrm{Cl}^{-}$conductance and stimulate additional iodide efflux from the cell; and (4) NaI buffer without agonists, to wash out and reverse agonist effects as well as re-quench SPQ fluorescence. The reversibility and re-quenching is also a good indicator of the viability of and level of dye within the cells throughout the entire experiment. The relative background for each cover slip was subtracted from the recorded arbitrary light unit measurements. The resultant data points are analyzed 
and plotted dependent upon the first recorded point which establishes the baseline.

\section{Nasal potential difference (NPD) assays on two different cf mouse models}

NPD assays were performed as described previously but were designed to specifically study and activate CFTR maximally. We performed experiments on all three CFTR genotypes in each mouse model. One mouse model was the $\triangle$ F508-CFTR mouse developed by Thomas and colleagues [48]. The second mouse model was the UNC knockout mouse that was corrected in the gastrointestinal tract by complementation with a fatty acid binding protein (FABP) promoter-driven CFTR construct. The lung and airways remain null for CFTR (a generous gift from Dr. Jeffrey Whitsett, M.D., Ph.D. to the UAB CF Center, [49]. Amiloride $(50 \mu \mathrm{M})$ was added in a standard Lactated Ringers in step 1 of the assay to inhibit all $\mathrm{Na}^{+}$absorptive pathways. In the continued presence of amiloride, a low $\mathrm{Cl}^{-}(6 \mathrm{mM})$ solution was perfused to gauge $\mathrm{Cl}^{-}$permeability of the nasal mucosa epithelium. Wild-type and heterozygous animals possessed a low $\mathrm{Cl}^{-}$response, while homozygous animals did not. In the presence of amiloride and in a low $\mathrm{Cl}^{-}$solution, adenosine and salbutamol (100 $\mu \mathrm{M}$ each) were added together to increase cyclic AMP maximally via their respective $G$ protein-coupled receptors that engage adenyl cyclase. Isoproterenol (Isoprel $^{\mathrm{m}}$ ) or albuterol (salbutamol) alone were not enough to maximally stimulate CFTR. It was adenosine together with a $\beta$-adrenergic agonist that gave us consistent cyclic AMP induction of CFTR above and beyond the low $\mathrm{Cl}^{-}$response. This modification was done based on the work of Clancy and colleagues on adenosine regulation of CFTR in mice and humans [50,51]. The change in PD, in the negative direction (hyperpolarization) during the low $\mathrm{Cl}^{-}$ phase and adenosine and salbutamol (cyclic AMP) phase of the recordings, was quantified from the strip-chart records. Ussing chamber assays were performed as described above on primary mouse tracheal epithelial cell monolayers derived from these mice.

\section{MTE monolayer culture and ussing chamber analysis}

After analysis of in vivo CFTR function by nasal PD in the three CFTR genotypes in each mouse model, tracheae were excised by surgery in anesthetized mice and were kept separated as to genotype. Tracheae were first washed in a CaMg-free PBS with $5 \mathrm{X}$ penicillin/streptomycin $(500 \mathrm{U} / \mathrm{ml}$ penicillin, $500 \mu \mathrm{g} / \mathrm{ml}$ streptomycin). Tracheae were then washed in a series of dishes containing CaMg-free DMEM/F12 medium with 5X penicillin/ streptomycin. Excess tissue was removed from the tracheae, and they were filleted open down the midline from the laryngeal cartilage to its base. The dissection was performed in the above DMEM/F12 Dissection
Medium. The filleted tracheae were then placed in CaMg-free DMEM/F12 medium with $2 \mathrm{X}$ penicillin/ streptomycin and $1 \mu \mathrm{g} / \mathrm{ml}$ protease type XIV and $0.1 \mu \mathrm{g} / \mathrm{ml}$ DNase I on ice. The tracheae were digested at $4^{\circ} \mathrm{C}$ overnight in this Digestion Medium without agitation. After the $18 \mathrm{~h}$ overnight digestion in the cold, tracheae were inverted in the tubes $15 \mathrm{X}$ to maximally dissociate cells. FBS (20\%) was then added to inactivate the enzymes, and the dissociated cells were placed into a separate tube on ice. The digested tracheae were then washed (with 15X tube inversion again) in mouse tracheal epithelial (MTE) cell Monolayer Maturation - CaMg-containing DMEM/F12 medium supplemented per $500 \mathrm{mls}$ of medium with $20 \%$ FBS (Life Technologies, Certified and Heat-Inactivated), 2X Pen/Strep, $5 \mathrm{mls}$ of L-glutamine (from 100X stock), $2 \mathrm{mls}$ of hydrocortisone (from $10 \mathrm{ml}$ stock solubilized in ethanol, Becton-Dickinson), $2 \mathrm{mls}$ of endothelial cell growth supplement (ECGS from $10 \mathrm{ml}$ stock, Becton-Dickinson), $2 \mathrm{mls}$ of bovine pituitary extract (BPE from $10 \mathrm{ml}$ stock, BectonDickinson), and $4 \mathrm{mls}$ of insulin-transferrin-selenium (ITS from $20 \mathrm{ml}$ stock, Becton-Dickinson). Washes were collected and placed on ice. Then, the tracheae were exposed to fresh Digestion Medium for $1 \mathrm{~h}$ at $37^{\circ} \mathrm{C}$. After the second digestion, the tubes were inverted 15X, FBS (20\%) was added to inactivate the enzymes, dissociated cells were collected in a separate tube, and washes with standard culture medium were performed as above. Four separate sets of tubes (two digestions, two washes) were centrifuged for 3$5 \mathrm{~min}$ to pellet any and all cells. Pellets were then obtained from all 4 phases of the MTE cell isolation. Then, cells were combined (still separated as to CFTR genotype), pelleted and resuspended in a minimal volume (50-100 $\mu$ l per filter support). Four filter supports can be seeded per 1 trachea. Filter supports were coated with CellTak and with a 1:10 diluted Vitrogen 100 solution (in CaMg-free PBS) that also contained $1 \mathrm{mg}$ human fibronectin (Becton-Dickinson) added into a $50 \mathrm{ml}$ total volume one day prior to seeding. The cell seeding day was deemed Day 0 . Cells were allowed to attach over an initial 3-day period with medium bathing both sides of the filter support. Then, on Day 3, medium was removed and only the basolateral (bottom) side of the filter support was fed to initiate air-fluid interface (AFI) culture. MTE monolayers were maintained in this way until leak of medium was no longer observed from the bottom to the top of the filter support. Visual inspection of the cells on the filter support when no leak was observed showed "doming" and "ridging" of a confluent monolayer. After this point in monolayer culture, $\mathrm{R}_{\mathrm{TE}}$ and $\mathrm{V}_{\mathrm{TE}}$ were monitored with a Voltohmeter (Millipore or World Precision Instruments). $R_{T E}$ above $1,000 \Omega \cdot \mathrm{cm}^{2}$ and a significant negative $\mathrm{V}_{\mathrm{TE}}$ were then measured on or after Days 8-10. We performed Ussing chamber analysis when the electrical parameters had plateaued in open-circuit measurements and did not increase further. 


\section{Statistics}

Explanation of quantification and statistical analysis of the data generated in all assays was explained in the context of the specific methods presented above.

\section{Results \\ Early Evidence of $\triangle$ F508-CFTR inhibition of wild-type CFTR function}

As a collaborative effort among multiple authors and laboratories involved in this study, a study was published in which optimization of transient transfection of polarized epithelial cell monolayers was performed [14]. The founding context of this work was that CFTR biogenesis, trafficking and function would be best studied in its native environment, the polarized human airway epithelial cell. During these studies, we observed that $\triangle \mathrm{F}$-CFTR expression in epithelia inhibited WT-CFTR driven cyclic AMPactivated $\mathrm{Cl}^{-}$channel activity, monolayer maturation, and regulation of chemokine release. These observations provided the rationale for designing and undertaking the studies described below.

\section{Is the expression of wild-type cftr altered by co- expression of $\Delta \mathrm{F} 508$-CFTR?}

To determine whether the processing of WT-CFTR is affected by the presence of $\triangle \mathrm{F}$-CFTR, we co-expressed the WT and mutant forms of CFTR in IB3-1 CF human airway epithelial cells that are null for detectable endogenous CFTR protein (Figure 1A). Examination of immunoprecipitated and PKA-decorated proteins on a 6\% SDS-PAGE gel showed that processing of a fixed amount of WT-CFTR was altered by increasing amounts of $\triangle$ F-CFTR. In native epithelia, CFTR is immunoprecipitated as two major forms. " $\mathrm{C}$ band" is a broad band between $160-180 \mathrm{kDa}$ that is the maturely glycosylated form of CFTR that successfully traffics through the secretory pathway to the apical plasma membrane. C band is the only form found when exogenous WT-CFTR was expressed alone in IB3-1 cells. "B band" is a tighter immaturely glycosylated band between $140-150 \mathrm{kDa}$ that is an ER form of CFTR. It is a single band in native epithelia and a doublet of bands in HEK-293 cells (see below). B band is the only band observed when exogenous $\triangle$ F-CFTR was expressed alone IB3-1 cells. In Figure $1 \mathrm{~A}$, as the amount of $\triangle \mathrm{F}-\mathrm{CFTR}$ cDNA was increased in the presence of a fixed amount of WTCFTR cDNA, there was decreased processing of the $\mathrm{C}$ band of WT-CFTR protein. Inhibition of $\mathrm{C}$ band formation was most notable when 4-8-fold more $\triangle \mathrm{F}$-CFTR plasmid was co-transfected versus WT-CFTR (refer to both examples in Figure 1A for different examples of the same dominant negative-like effect. We speculate that this is due to the increased rate of degradation in the ER of $\triangle$ F-CFTR versus WT-CFTR $[44,45]$. However, when the same co-transfection experiment was performed in the heterologous human embryonic kidney cell line, HEK-293 T, over-expression of $\triangle \mathrm{F}$-CFTR was without effect on WT-CFTR processing (Figure 1B). These results suggest that CFTR processing may be different in epithelial cells versus heterologous cells and that epithelial-specific accessory proteins may be essential for driving this $\triangle$ F-CFTR inhibitory interaction with WTCFTR.

\section{Is this dominant negative-like effect of $\triangle F 508$-CFTR on WT-CFTR dependent upon Its PDZ motif?}

To assess specificity of this $\triangle \mathrm{F}$-CFTR/WT-CFTR interaction, we co-expressed $\triangle \mathrm{F}$-CFTR with a fixed amount of $\triangle$ TRL-CFTR, a CFTR variant lacking the C-terminal PDZ binding motif but that processes efficiently through the Golgi to the plasma membrane [52]. The CFTR PDZ motif is critical for CFTR interactions with PDZ binding proteins such as EBP50 (NHERF), E3KARP, CAP-70, CAL, etc., connects CFTR to larger macromolecular complexes in organelle and plasma membranes, and influences CFTR function [35-41,53]. In contrast to dominant negative-like effects on WT-CFTR by $\Delta \mathrm{F}$ CFTR, increasing amounts of $\triangle F$-CFTR failed to affect the maturation of $\triangle$ TRL-CFTR in IB3-1 CF human airway epithelial cells (Figure 1C). Summary data is also presented from multiple experiments (Figure 1C). $\Delta \mathrm{F}$ CFTR was also without effect on $\triangle$ TRL-CFTR in HEK$293 \mathrm{~T}$ cells (data not shown). These results suggest that the PDZ motif of CFTR is critical to the inhibitory influence of $\triangle$ F-CFTR on WT-CFTR at the level of the ER.

\section{Is this a specific and exclusive interaction between $\triangle$ F508-CFTR and WT-CFTR?}

We wished to take addition steps to provide specificity and exclusivity for this macromolecular complex and PDZ motif-driven $\triangle$ F-CFTR/WT-CFTR inhibitory interaction, we expressed increasing amounts of G551DCFTR with a fixed amount of WT-CFTR. We observed only accumulating amounts of $\mathrm{C}$ band that did not appear to saturate during the co-expression of this mutant and WT-CFTR (Figure 2A). It is important to underscore the fact that G551D-CFTR is not an ER retention mutant but rather is processed normally to the plasma membrane. Rather, G551D-CFTR is a dysfunctional $\mathrm{Cl}^{-}$ channel because ATP binding and gating to its NBDs is impaired. This is why the CFTR potentiator drug, VX770 (ivacaftor, Kalydeco) [54] is markedly effective in G551D-CFTR patients, while the CF corrector drug, VX809, corrects/rescues $\triangle F$-CFTR from ER quality control and is without effect on G551D-CFTR patients [55,56]. We also wished to determine whether this dominant negative-like effect of $\triangle$ F-CFTR was not non-specific to other glycosylated membrane proteins. The epithelial 


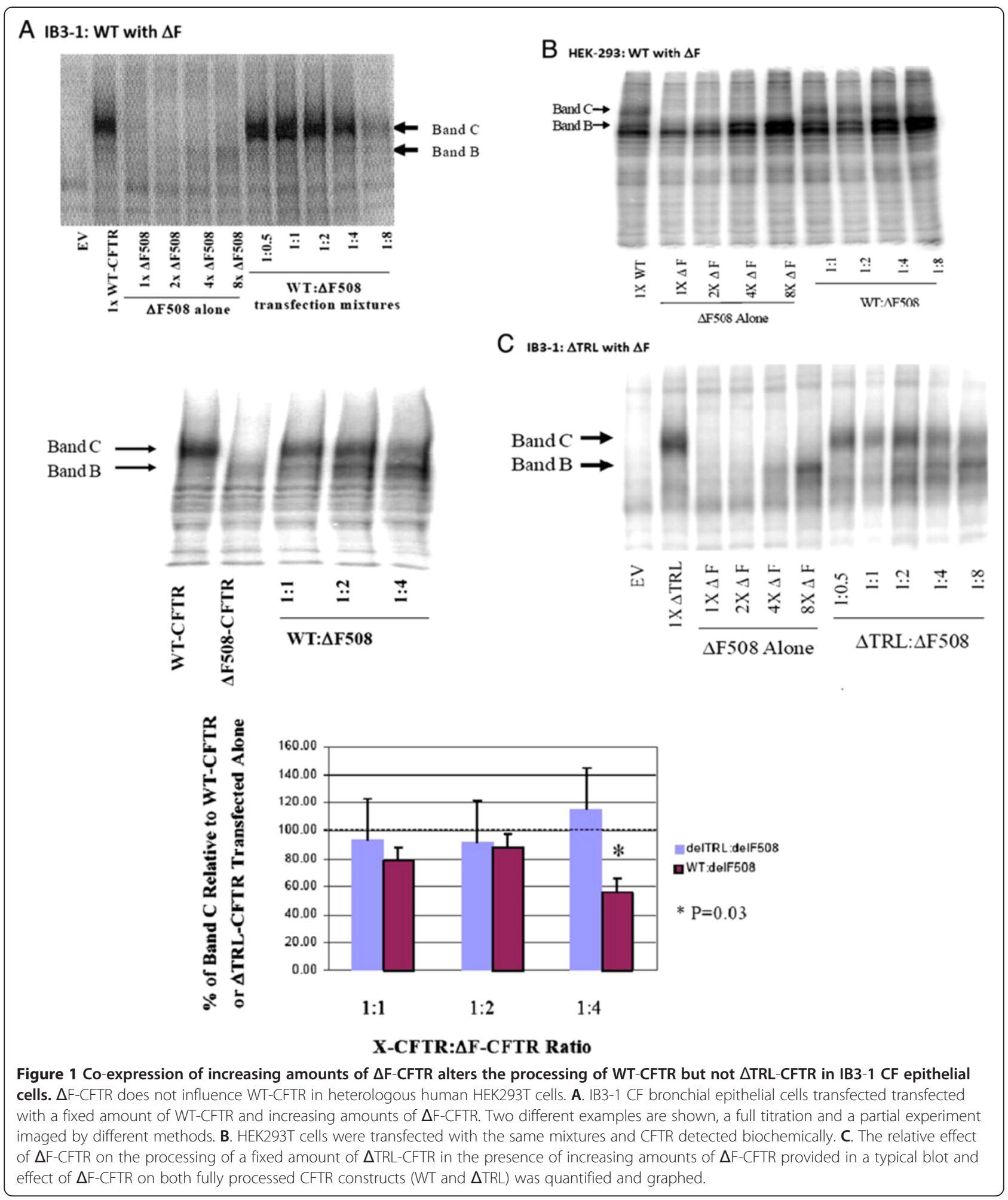

$\mathrm{P}_{2} \mathrm{X}_{4}$ purinergic receptor calcium entry channel also has immature $(\sim 40 \mathrm{kDa})$ and maturely glycosylated (60$65 \mathrm{kDa}$ ) forms and robust expression in both CF and non-

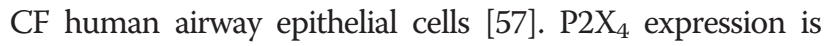
robust in Western blot analysis and no difference in expression of either form of the receptor channel was observed with increasing amounts of $\triangle \mathrm{F} 508-\mathrm{CFTR}$ plasmid expression (Figure $2 \mathrm{~B}$ ). These data, along with other internal controls above in Figure 1, suggest that ER stress is not a cause of $\triangle$ F-CFTR inhibition of WT-CFTR processing. 


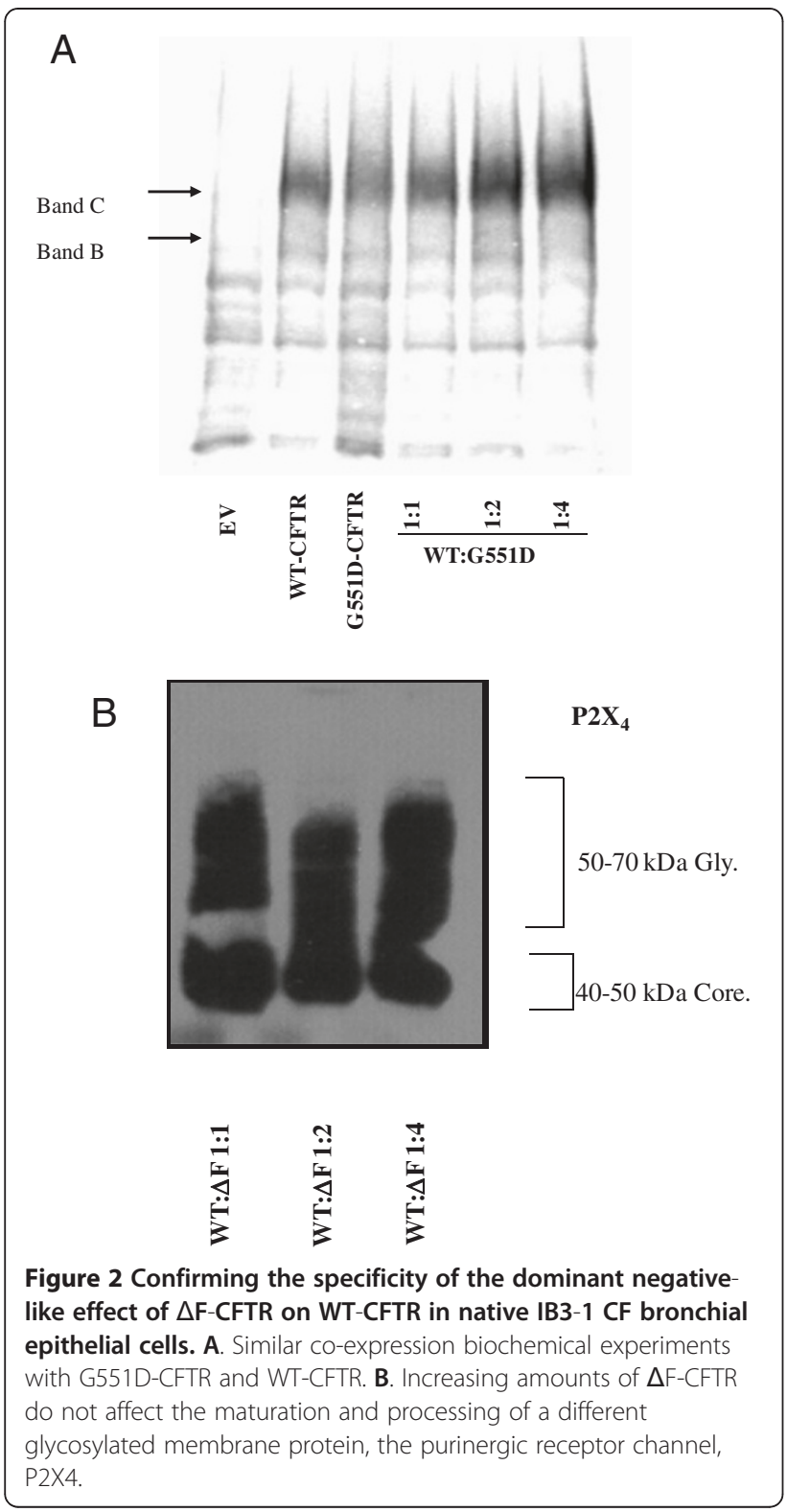

\section{Is the function of WT-CFTR altered by co-expression of} $\Delta$ F-CFTR?

To complement the biochemical experiments above, we also assayed for CFTR $\mathrm{Cl}^{-}$channel function with the SPQ halide efflux assay [47]. IB3-1 cells were co-transfected with increasing amounts of $\triangle \mathrm{F}$-CFTR versus a fixed amount of WT-CFTR as above. These cells were later incubated with the halide-sensitive dye, SPQ, overnight in medium prior to the experiment 2 days after transient transfection. Cover slips of transiently transfected cells were mounted into a perfusion chamber and bathed in sodium iodide (NaI) buffer to maintain quenching of SPQ fluorescence. First, the cells were challenged with $\mathrm{NaNO}_{3}$ buffer, which dequenchs SPQ and assays for basal halide efflux which is augmented by WT-CFTR expression.
Second, a cocktail of cyclic AMP agonists (CPT-cAMP, $200 \mu \mathrm{M}$; forskolin, $2 \mu \mathrm{M}$; IBMX, $100 \mu \mathrm{M}$ ) was perfused into the chamber in $\mathrm{NaNO}_{3}$ buffer to stimulate additional CFTR $\mathrm{Cl}^{-}$channel activity (measured by increased halide efflux). Mock and $\triangle$ F-CFTR-expressing cells failed to respond to $\mathrm{NaNO}_{3}$ buffer alone or to the cocktail of cyclic AMP agonists (Figure 3A). In contrast, WT-CFTRtransfected cells responded markedly to both $\mathrm{NaNO}_{3}$ buffer alone or to the cyclic AMP cocktail (Figure 2A). However, in the co-expression experiments, increasing amounts of $\triangle$ F-CFTR inhibited wild-type CFTR activity in an apparent dose-dependent manner (Figure 3A). The functional assay showed complete inhibition with 4:1 $\Delta \mathrm{F}$ CFTR:WT-CFTR expression, while biochemical assays showed complete inhibition with 8:1 $\triangle$ F-CFTR:WT-CFTR expression. In contrast, similar experiments in the HEK293 T system showed no inhibition of WT-CFTR with increasing amounts of $\triangle \mathrm{F}-\mathrm{CFTR}$ (Figure $3 \mathrm{~B}$ ). Taken together, these data suggests that $\triangle \mathrm{F}$-CFTR interacts with WTCFTR during its processing and inhibits its functional expression in the plasma membrane in a dominant negative-like manner in human airway epithelial cells.

Are the processing and function of WT-CFTR altered by stable expression of $\triangle \mathrm{F}-\mathrm{CFTR}$ in a polarized non-CF human airway epithelial cell line that expresses endogenous CFTR?

One potential problem of the co-transfection and coexpression studies above was the necessity to transiently transfect with large quantities of plasmid DNA and to over-express $\triangle F$-CFTR in order to inhibit WT-CFTR processing and function. Again, we speculate that this is likely necessary to overcome the increased rate of degradation of $\triangle \mathrm{F}$-CFTR protein versus WT-CFTR protein. However, to account for this issue and to approach this inhibitory interaction differently, we employed the wellcharacterized WT-CFTR-expressing airway epithelial cell line, CALU-3, and stably transfected $\triangle F-C F T R$ into it, generating several clones that were $\mathrm{CF}$ heterozygous cell lines. We also chose the CALU-3 cell line because of its high level of endogenous WT-CFTR expression and its ability for form polarized cell monolayers when grown on filter supports. Upon expansion and cryopreservation of the clones, CFTR biochemistry was performed. Parental CALU-3 cells expressed the C band form of CFTR almost exclusively (Figure 4A); all clones stably expressing $\triangle F-C F T R$ as an engineered heterozygous CF cell expressed both $\mathrm{B}$ band and $\mathrm{C}$ band forms and with reduced $\mathrm{C}$ band amounts in all clones. To assay for CFTR $\mathrm{Cl}^{-}$channel function, we grew parental CALU-3 cells and $\triangle \mathrm{F}$-CFTR-expressing CALU-3 clones on permeable filter supports for Ussing chamber analysis of short-circuit current $\left(\mathrm{I}_{\mathrm{SC}}\right)$. Monolayers with a transepithelial resistance $\left(R_{T E}\right)$ at or above $1,000 \Omega \cdot \mathrm{cm}^{2}$ were used in these experiments. In all experiments (Figure $4 \mathrm{~B}$ 

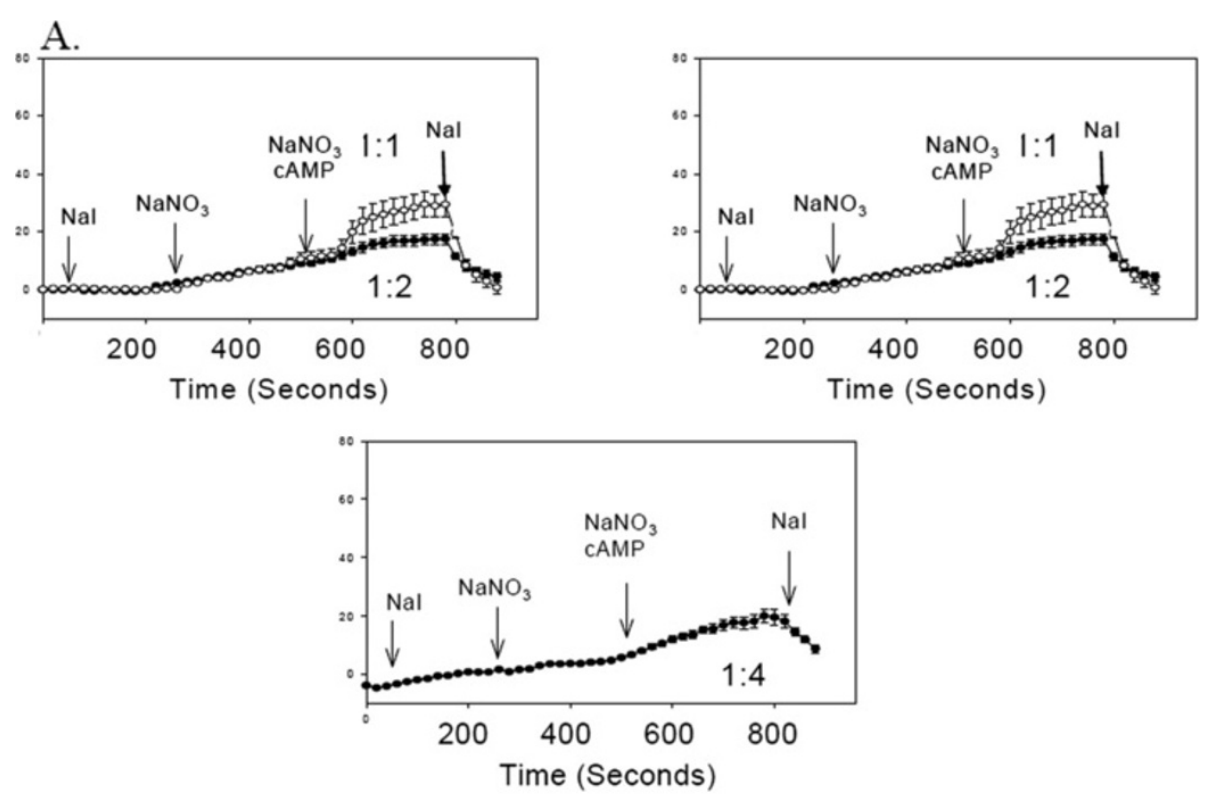

B.
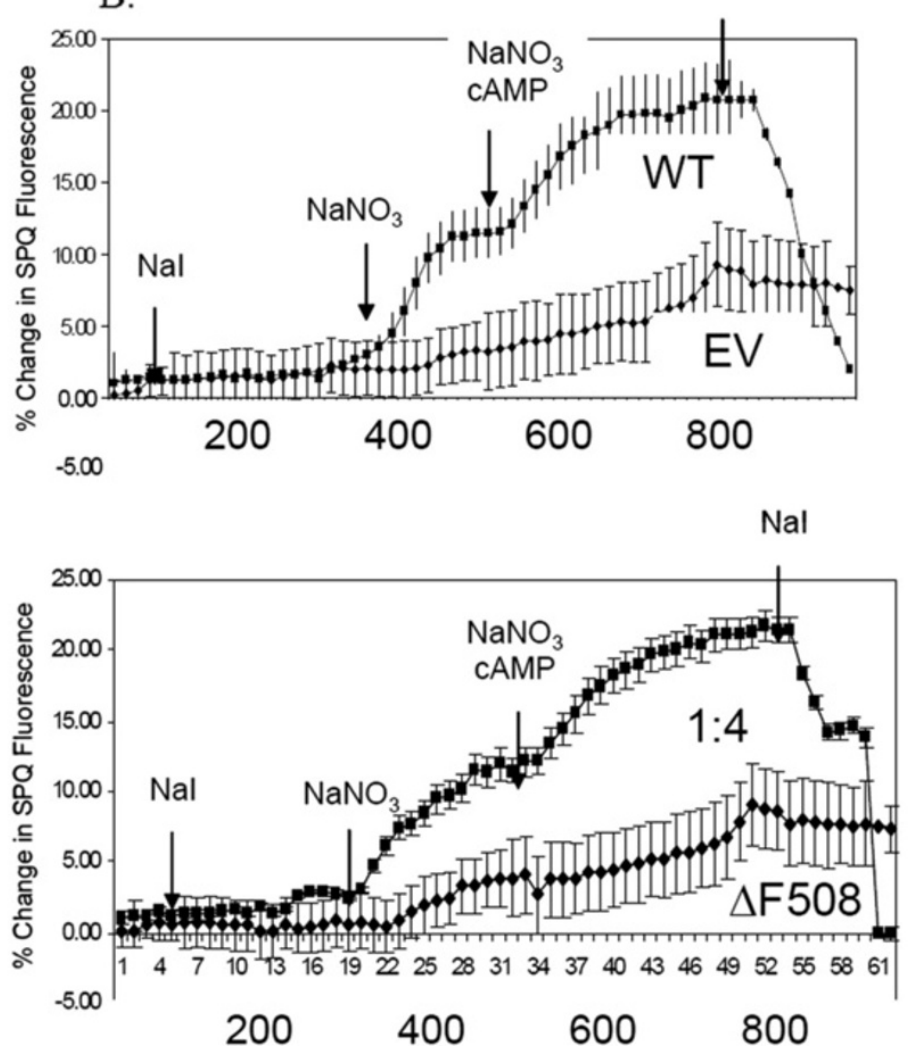

Figure 3 Co-expression of increasing amounts of $\triangle$ F-CFTR alters the function of WT-CFTR in IB3-1 CF epithelial cells but not in HEK293T cells. A. IB3-1 cells are seeded on Vitrogen coated coverslips and transiently transfect in the manner previously described in Figure 1. Twenty-four hours after transfection the cells are loaded with the halide sensitive dye, SPQ, overnight. The cells relative fluorescence is then measured while incubated in three different buffers: $\mathrm{Nal}, \mathrm{NaNO}_{3}$, and $\mathrm{NaNO}_{3}$ with cAMP agonists, and then back into Nal. B. HEK293T cells were seeded on Vitrogen free coverslips and transfected, loaded, and measured as previously described in $\mathbf{A}$. 


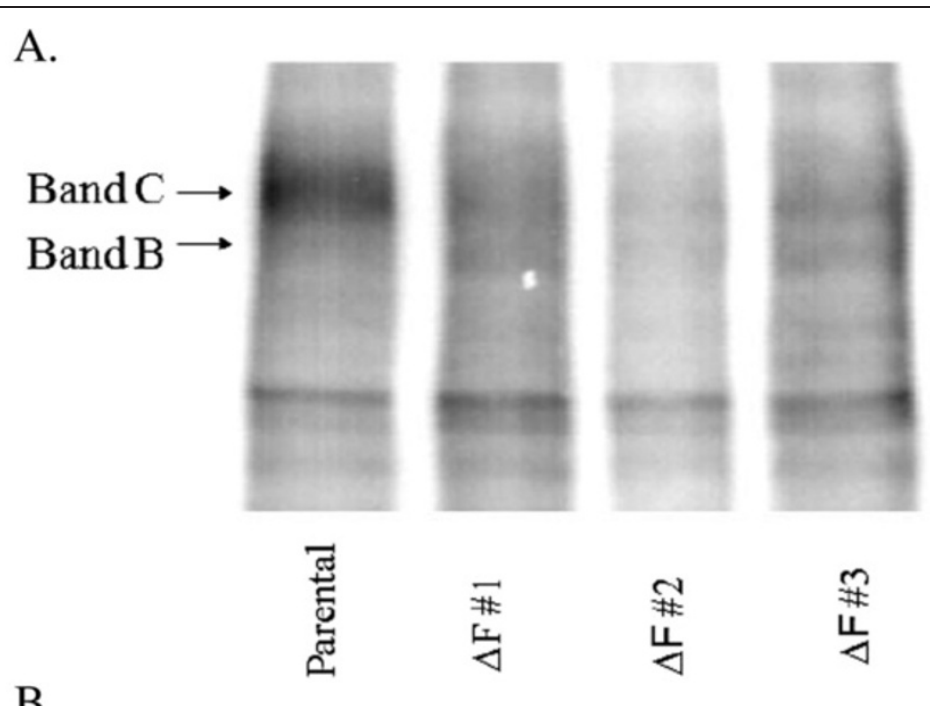

B.
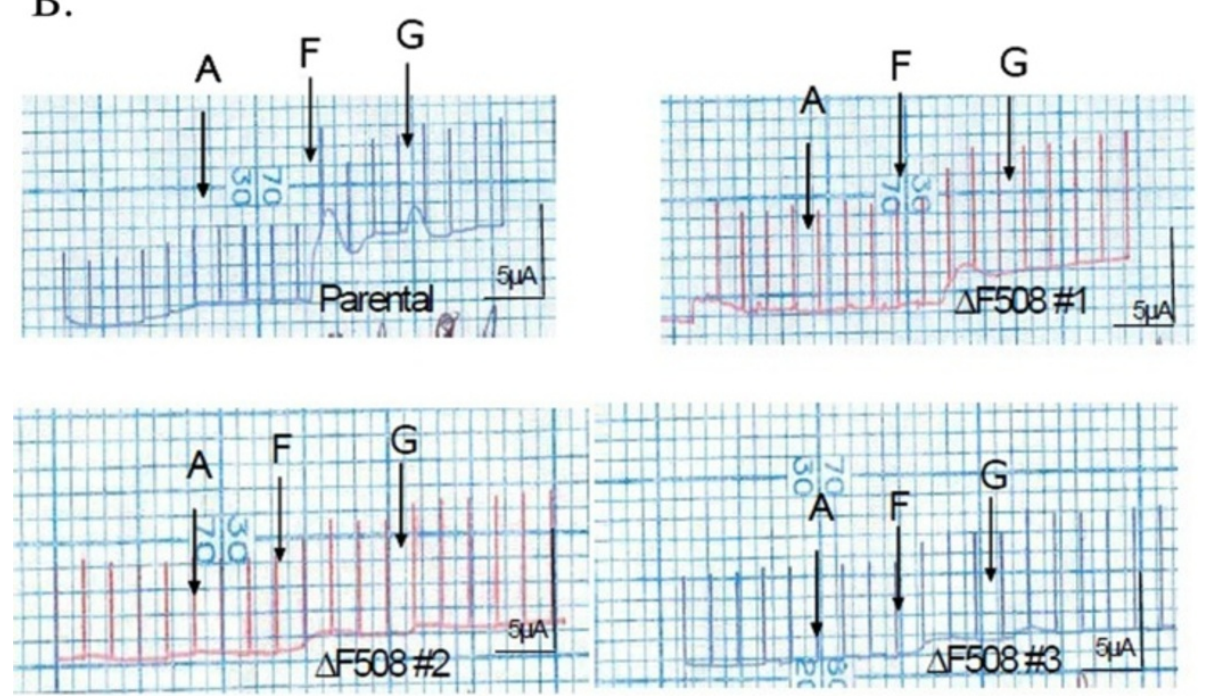

C.

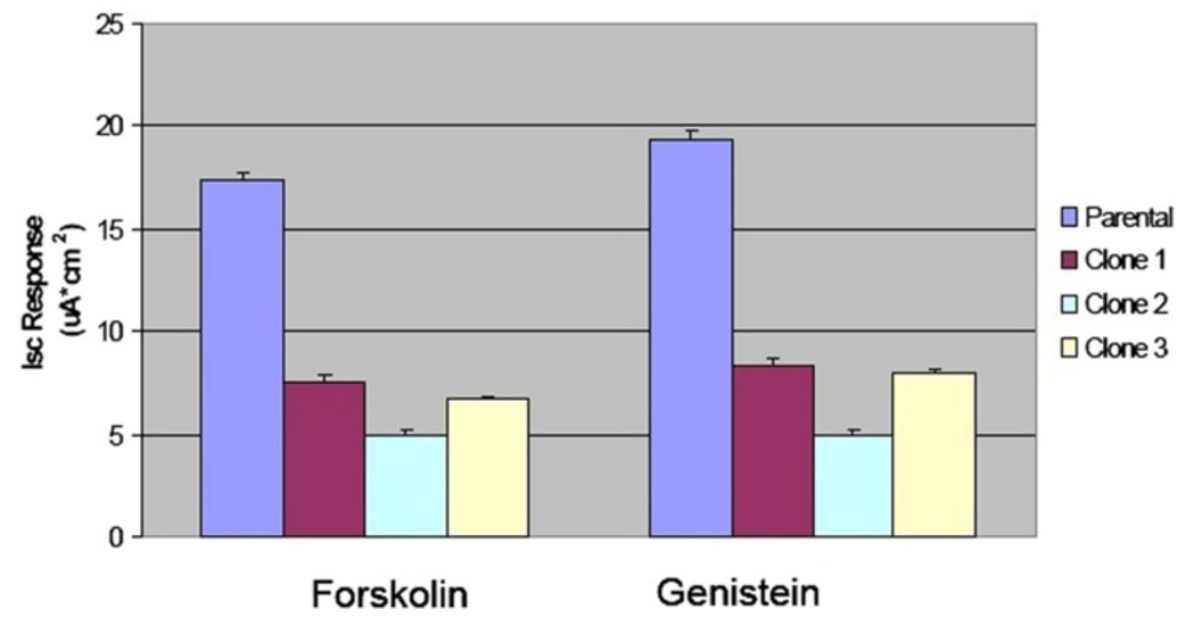

Figure 4 (See legend on next page.) 
(See figure on previous page.)

Figure 4 Stable Transfection of $\triangle$ F508-CFTR into CALU-3 non-CF epithelial cells alters the processing and function of endogenous WTCFTR. A. CFTR was IP'd from parental and stably transfected CALU-3 cells. The samples were then phosphorylated and resolved as described previously. B. Parental and stably transfected CALU-3 cells were seeded on $6.5 \mathrm{~mm}$ Vitrogen coated permeable filter supports. The CALU-3 monolayers were then allowed to reach a transepithelial resistance $\left(R_{T E}\right)$ of $2,000 \Omega \cdot \mathrm{Cm}^{2}$ or above prior to experimentation. ISC is then measured in response to $10 \mu \mathrm{M}$ amiloride, $20 \mu \mathrm{M}$ forskolin and $50 \mu \mathrm{M}$ genistein added apically via an Ussing chamber. Typical traces are shown. C. Summary analysis of parental and stably transfected CALU-3 cells IsC response to agonists.

and $\mathrm{C})$, amiloride $(10 \mu \mathrm{M})$ was added to block any $\mathrm{Na}^{+}$ absorption which is minimal in this epithelial cell model. Typical traces are shown for a parental CALU-3 cell monolayer and for multiple stable clones expressing $\Delta \mathrm{F}-$ CFTR as an engineered heterozygous cell model coexpressing WT-CFTR and $\triangle$ F-CFTR endogenously. After amiloride pretreatment, forskolin $(10 \mu \mathrm{M})$ was added to stimulate CFTR-dependent $\mathrm{Cl}^{-}$secretion via cyclic AMP. Then, genistein $(50 \mu \mathrm{M})$ was added to open any and all remaining CFTR $\mathrm{Cl}^{-}$channels in the apical membrane. While parental CALU-3 cell monolayers responded with an averaged $5 \mu \mathrm{A}$ to forskolin and an additional $1 \mu \mathrm{A}$ to genistein in the presence of forskolin (Figure 4B), stable clones co-expressing both WT-CFTR and $\triangle$ F-CFTR endogenously responded only half as well or less so than parental cell monolayers. Figure $4 \mathrm{C}$ provides the summary data for this Ussing chamber analysis. Taken together, these data show that equivalent expression of WT-CFTR and $\triangle F 5$-CFTR endogenous to an airway epithelial cell leads to inhibition of WT-CFTR processing and, thus, function. Stable expression of both forms of CFTR also obviated the need to express more $\triangle \mathrm{F}$-CFTR in a transient transfection versus WT-CFTR to observe the same dominant negative-like effect.

\section{Is the function of WT-CFTR altered by $\triangle$ F-CFTR in WT- CFTR/AF-CFTR heterozygous 'carrier' mice in vivo and in vitro?}

In vitro results above suggested a dominant negative-like inhibition of WT-CFTR by $\triangle$ F-CFTR that was specific to this most common ER retention folding mutant and observed in native human airway epithelial cells. Studies of human patients populations, where the WT (normal), heterozygous carrier, and homozygous CF patients were analyzed as separate groups, has shown three different phenotypes for a given endpoint in past studies. We wished to confirm our in vitro studies with in vivo nasal potential difference (NPD) measurements in the $\triangle F 508$ CFTR mouse [48]. A previous argument explaining partial CF heterozygous defects was simply gene dilution (e.g., 1 copy or allele of WT-CFTR versus 2 copies). As such and in parallel, we performed NPD assays on a bitransgenic CF mouse model generously provided to our UAB CF Center Mouse Transgenic CORE by Dr. Jeffrey Whitsett. This model is a CFTR knockout mouse that is corrected in the gastrointestinal tract with a fatty acid binding protein (FABP) promoter-driven CFTR construct [49]. In this bitransgenic mouse, however, the lung and airways remain null for CFTR in the CF $(-/-)$ homozygous condition, the heterozygous mice have 1 allele of CFTR (+/-), and the WT mice have two alleles of CFTR $(+/+)$. This is different from the $\triangle$ F-CFTR mouse, where the WT mice will be WT/WT, the heterozygotes will be $\mathrm{WT} / \Delta \mathrm{F}$, and the homozygotes will be $\Delta \mathrm{F} / \Delta \mathrm{F}$.

Figure 5A shows typical NPD recordings from all 3 genotypes of the $\triangle F-C F T R$ mouse. Summary data that includes and illustrates results from all mice studied in shown in Figure 5B. Homozygous mice failed to respond to the low $\mathrm{Cl}^{-}$solution, indicating a lack of $\mathrm{Cl}^{-}$permeability in the nasal mucosa (Figure 5A and B). Homozygotes also failed to respond significantly to cyclic AMP agonists, adenosine $(100 \mu \mathrm{M})$ and albuterol (salbutamol, $100 \mu \mathrm{M}$ ) (Figure 5A and B), although a small response was noted a subset of mice (Figure $5 \mathrm{~B}$ ). In contrast, WT mice within the $\triangle \mathrm{F}$-CFTR litters responded most vigorously to both the low $\mathrm{Cl}^{-}$maneuver and to the dual cyclic AMP agonists (Figures 5A and B). It should be noted that the inclusion of adenosine was essential for these studies, because Isoprel or salbutamol alone failed to elicit as large or as reproducible responses in the NPD assay. This modification was undertaken based on the work of our colleague and collaborator, Dr. JP Clancy et al., on adenosine regulation of CFTR [50,51]. Notably, the $\triangle$ F-CFTR heterozygous mice had an intermediate phenotype between WT mice and homozygous mice with regard to the low $\mathrm{Cl}^{-}$and cyclic AMP-induced responses (Figures 5A and B). Both hyperpolarization responses were significantly less than WT. These in vivo NPD data suggest that there is a decrement in CFTR Cl${ }^{-}$ channel activity in heterozygous $\triangle \mathrm{F}$-CFTR carrier mice versus WT mice when assessed across 6 different litters.

To derive closely paired in vitro data from these litters of $\triangle \mathrm{F}-\mathrm{CFTR}$ mice, tracheae were excised from these same mice in which CFTR NPD measurements were performed previously to isolate and establish mouse tracheal epithelial (MTE) cell monolayers grown on permeable filter supports in primary culture. Typical recordings of $\mathrm{I}_{\mathrm{SC}}$ from all 3 genotypes from $\triangle \mathrm{F}-\mathrm{CFTR}$ mouse model are shown in Figure 6A. Summary data are shown in Figure 6B. As in in vivo NPD assays above, WT MTE monolayers gave the most vigorous response to forskolin and genistein, while heterozygous MTE 


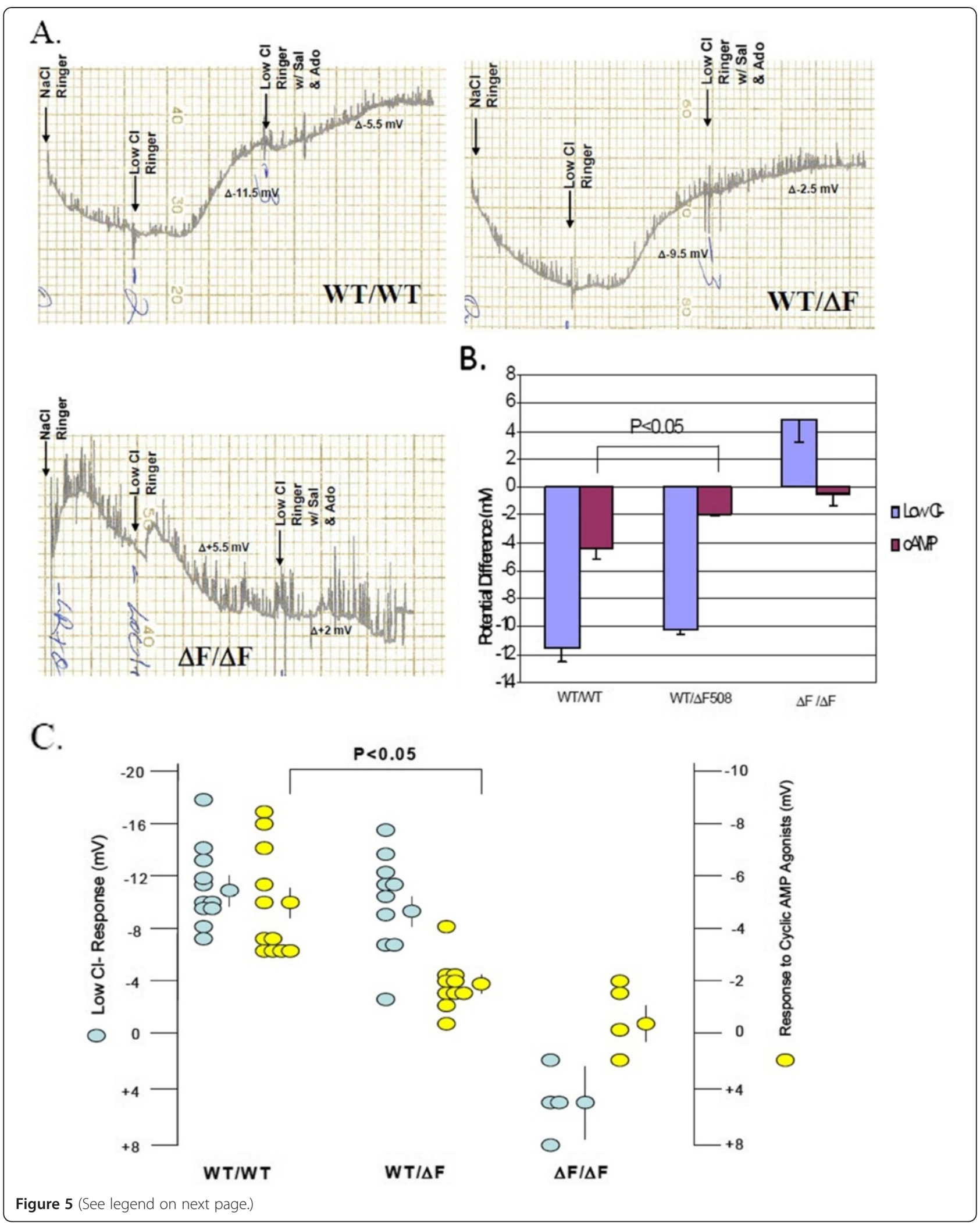


(See figure on previous page.)

Figure 5 Nasal Potential Difference is altered by $\Delta$ F508-CFTR in WT- CFTR/ $\Delta$ F508-CFTR Heterozygous mice. A. Nasal Potential Difference Assays (NPD) were performed on the three genotypes of the $\Delta F 508$ mice: WT/WT, WT/ $\mathrm{F}$, and $\Delta F / \Delta F$. NPD recordings were measured for each genotype in the presence of normal Ringer's solution, low $\mathrm{Cl}$ - ringer's solution, and then low $\mathrm{Cl}$ - Ringer's solution containing the CAMP agonist salbutamol $(100 \mu \mathrm{M})$ and adenosine $(100 \mu \mathrm{M})$. B. Summary data of the results illustrated in $\mathbf{A}$. C. Scatterplot representation of the NPD

measurements performed in the 3 genotypes of the $\Delta \mathrm{F} 508$ mice.

monolayers responded less well and homozygous $\Delta \mathrm{F}$ CFTR MTE monolayers failed to respond altogether (Figure $6 \mathrm{~A}$ and $\mathrm{B})$. In a subset of recordings, glibenclamide $(100 \mu \mathrm{M})$ inhibited the CFTR-mediated secretory $\mathrm{Cl}^{-}$current (data not shown). Taken together, these data are similar to results derived from in vivo NPD measurements of the same mice and suggest that CFTR activity is partially attenuated in $\mathrm{WT} / \Delta \mathrm{F}$ heterozygous $\mathrm{MTE}$ monolayers versus WT/WT controls.

Our parallel CF mouse model was the FABPXCFTR gutcorrected UNC knockout mouse that remains null for the lung and airways. In this case, the WT controls in these litters have 2 WT CFTR alleles, the heterozygous mice have 1 copy of WT CFTR, and the homozygous mice are null

A
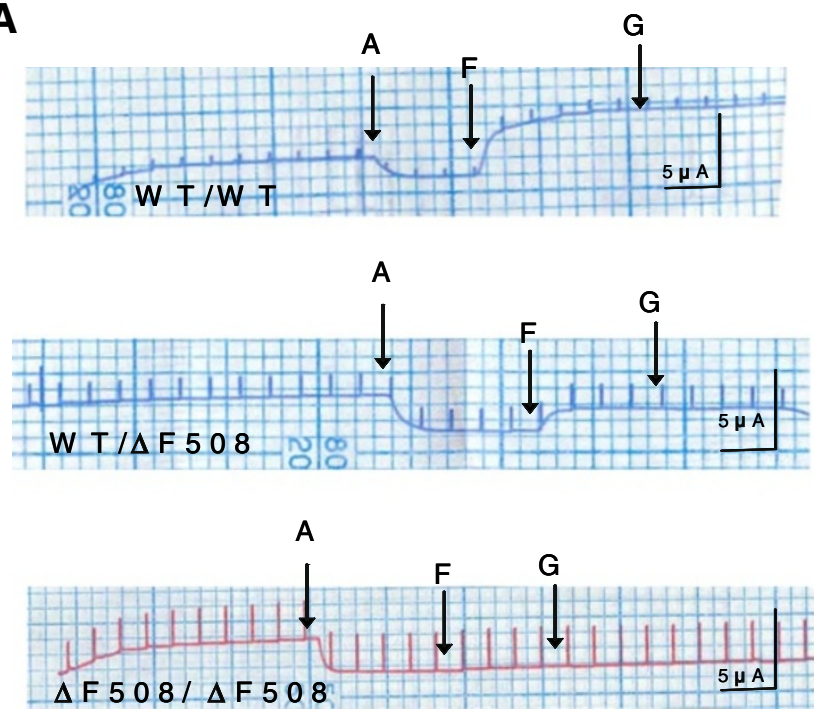

B

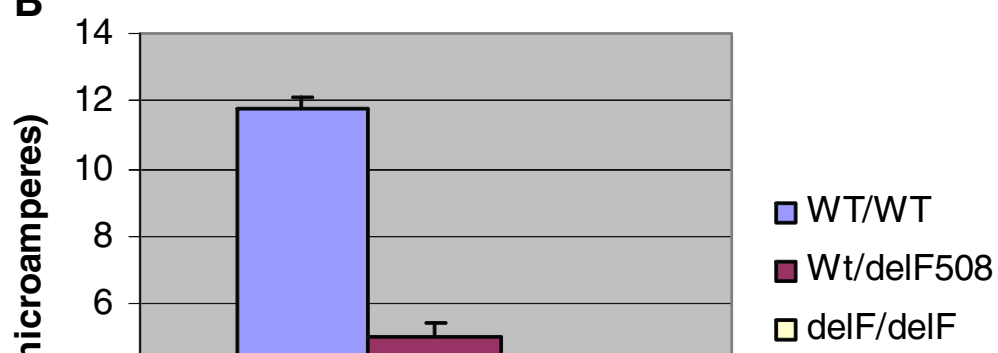

Figure 6 WT-CFTR function is altered by $\triangle$ F508-CFTR in WT-CFTR/DF508-CFTR heterozygous MTE A. Mouse tracheal epithelial cells (MTE) were seeded on Vitrogen coated filter inserts as previously described. On day three, the cells are grown in an air/liquid interface: media on the basolateral side but no media on the apical side. The RTE of the MTE monolayers are allowed to reach $1000 \Omega \cdot \mathrm{cm}^{2}$ or above prior to experimentation The MTE monolayer I IS current response to amiloride, forskolin, and genistein are then measured and record ed. B. Summary of the $\mathrm{I}_{\mathrm{SC}}$ data of the three genotypes of the $\Delta \mathrm{F} 508$ MTE monolayers. Homozygous cell monolayers failed to respond altogether and the summary Isc response was equal to zero. 
for CFTR. This is an important parallel study to the one above because $\triangle \mathrm{F}$-CFTR is not expressed in this mouse model. Figure 7A shows typical NPD recordings from all three CFTR genotypes in the Cincinnati bitransgenic mice. In this case, 1 copy of CFTR appeared sufficient for full function. There was no difference in low $\mathrm{Cl}^{-}$or cyclic
AMP agonist response between the WT and heterozygous mice (Figure 7A,B,C). Homozygous mice failed to respond to either maneuver (Figure 7A,B,C). Figure 7B is a scatterplot which represents the response of each mouse to low $\mathrm{Cl}^{-}$and cAMP agonists segregated to genotype. Results from all mice are shown in the summary data (Figure 7C).

A.

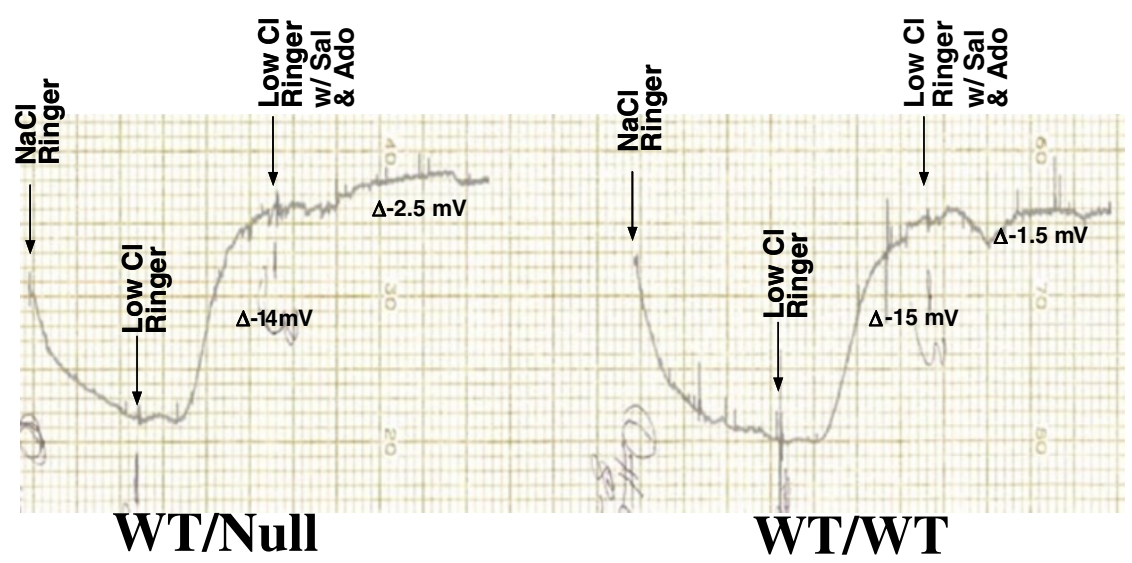

B.

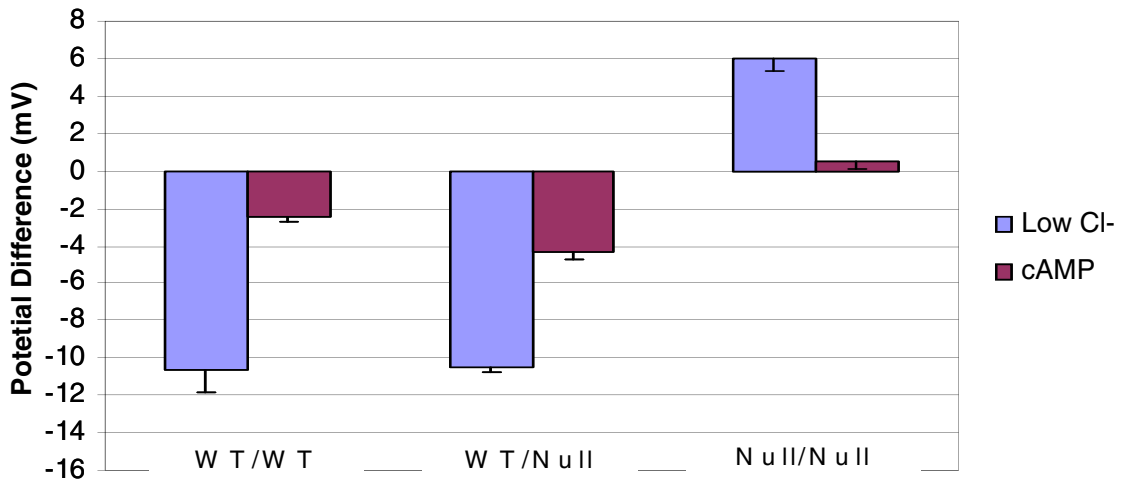

C.
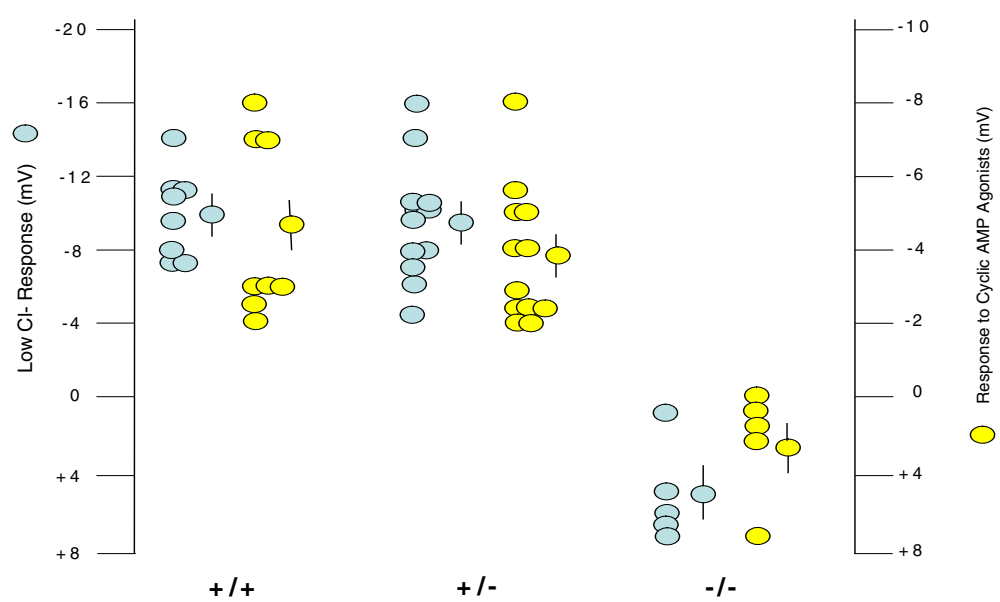

Figure 7 WT-CFTR function is not affected by the null CFTR allele in the Cincinnati WT-CFTR/Null mice. A. Nasal Potential Difference Assays (NPD) were performed on the three genotypes of the mice: WTMT, WT/null, and null/null. NPD recordings were measured for each genotype in the presence of normal Ringer's solution, low $\mathrm{Cl}$ - ringer's solution, and then low $\mathrm{Cl}$ - Ringer's solution containing the CAMP agonist salbutamol $(100 \mu \mathrm{M})$ and adenosine $(100 \mu \mathrm{M})$. B. Summary data of the results illustrated in $\mathbf{A}$. $\mathbf{C}$. Scatterplot which represents the NPD response of each mouse to low $\mathrm{Cl}$ - and CAMP agonists segregated to genotype. 
These data suggested that 1 CFTR allele is enough for full function in an epithelium and in the absence of the $\Delta \mathrm{F}$ CFTR mutation.

We then established MTE monolayers from tracheae of the same mice in the Cincinnati bitransgenic mouse litters. Figure $8 \mathrm{~A}$ shows representative $\mathrm{I}_{\mathrm{SC}}$ traces, Figure $8 \mathrm{~B}$ shows the summary data, and Figure $8 \mathrm{C}$ is a scatterplot which represents the response of each mouse to low $\mathrm{Cl}^{-}$and cAMP agonists segregated to genotype. Again, WT and heterozygous MTE monolayers had a similar response to both forskolin and genistein. Homozygous MTE monolayers did not respond to either agonist. Taken together, it is important to note that there is no decrement in overall WT-CFTR function when the number of CFTR alleles is reduced from 2 to 1 , suggesting again that $\triangle \mathrm{F}$-CFTR is a dominant negative inhibitor of WT-CFTR in airway epithelia.

\section{Discussion}

The results indicate that $\triangle \mathrm{F}$-CFTR alters the processing and function of WT-CFTR in a dominant negative manner when co-expressed in a CF human airway epithelial cell. This dominant negative effect required CFTR's PDZ-

A.
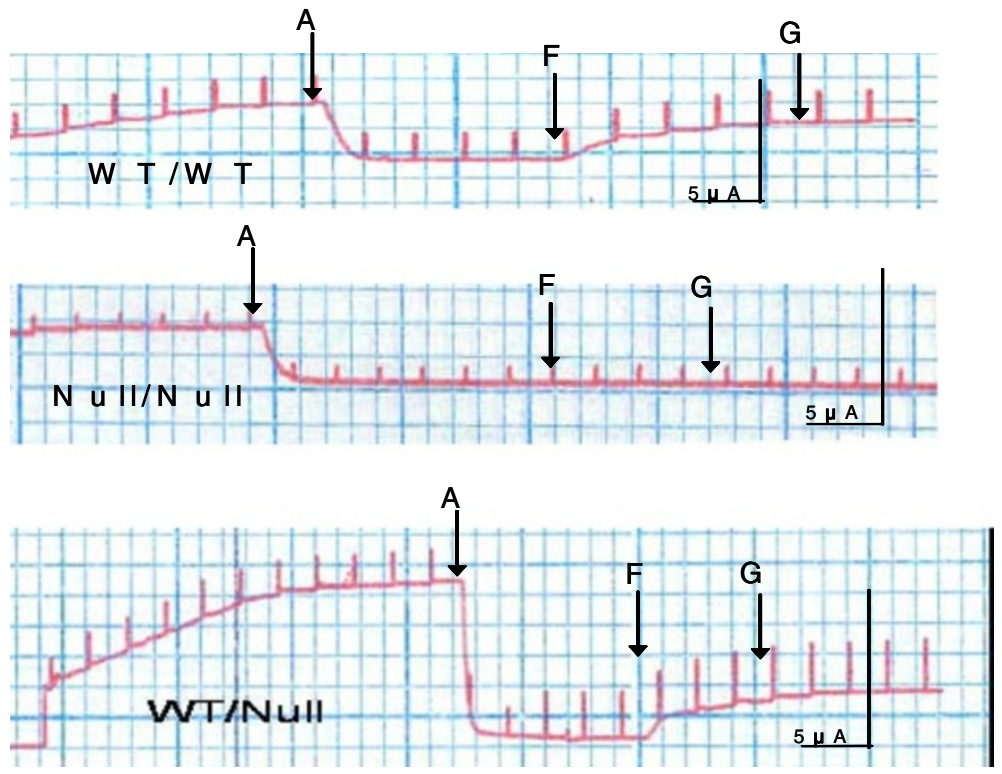

B.

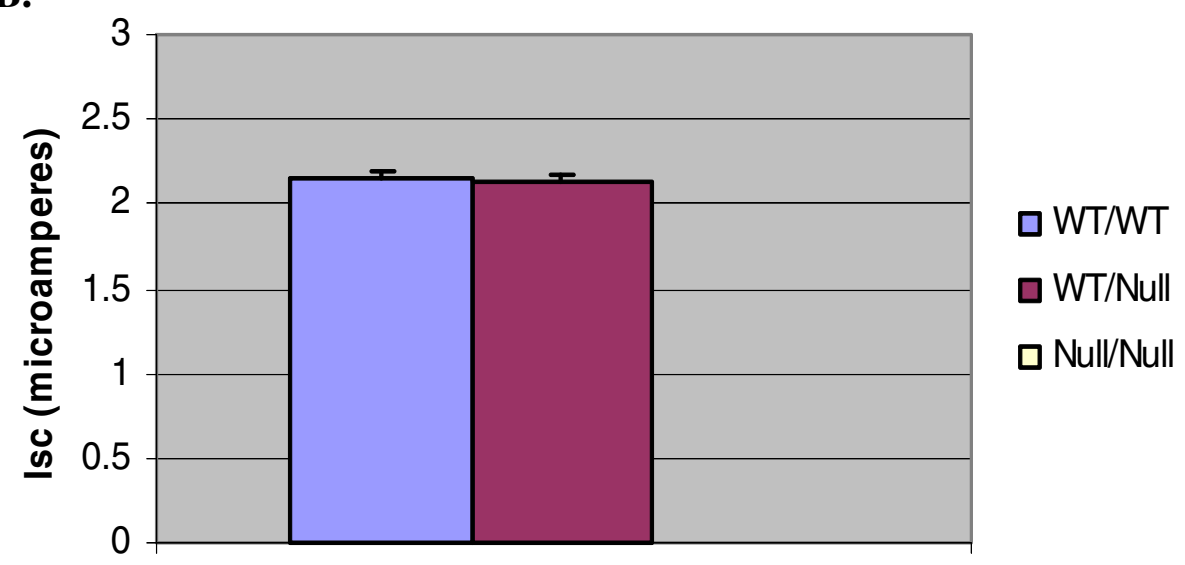

Isc Response

Figure 8 WT-CFTR function is not altered by the null CFTR allele in the Cincinnati WT-CFTR/null MTE. A. Mouse tracheal epithelial cells (MTE) were seeded on Vitrogen coated filter inserts as previously described. On day three, the cells are grown in an air/liquid interface: media on the basolateral side but no media on the apical side. The RTE of the MTE monolayers are allowed to reach $1000 \Omega \cdot \mathrm{cm}^{2}$ or above prior to experimentation The MTE monolayer Isc current response to amiloride, forskolin, and genistein are then measured and recorded. B. Summary of the $I_{S C}$ data of the three genotypes of the bitransgenic MTE monolayers. 
binding motif on its C-terminal end. Such an effect of $\Delta F$ CFTR on WT-CFTR could be conferred theoretically by direct protein-protein interaction within a CFTR dimer or multimer, the association of and regulation by accessory proteins (i.e., PDZ binding proteins) for processing, trafficking and function, and/or the association of and regulation by necessary ER chaperones for protein folding.

With these three main biochemical factors impacting upon CFTR biology in native epithelia, we present a single unifying hypothesis to defend this effect in native epithelia. First and foremost, this hypothesis is driven by the fact that our observations hold in native epithelia. Throughout our collective work over the last 15 years, we continue to champion the idea that CFTR functions differently and is processed differently in native human epithelial cell platforms versus non-human or human heterologous cell platforms. CFTR is a limited copy mRNA and protein in native epithelia. Given the copious data on CFTR monomer versus dimer versus larger multimer, we are inclined to agree that CFTR is a monomer; however, that does not mean that CFTR cannot be multimeric in nature. Our central hypothesis speaks to this idea and is predicated on the finding that CFTR resides in a large macromolecular signaling complex that is driven in part by its C-terminal PDZ binding motif. The importance of the PDZ motif has been supported mainly by data generated in native and polarized epithelial cell platforms. There is also evidence in native epithelia for PDZ-interacting proteins being involved in processing and trafficking of CFTR [35-41,53]. Following on these suppositions in a logical manner, ER resident chaperones and the supportive cytoskeleton would be involved actively in the folding and placement of the multiple proteins within this CFTR-resident macromolecular complex. Our hypothesis also assumes that multiple copies (at least 2 copies) of the CFTR protein are processed at the ER, trafficked through the Golgi, and functional at the apical plasma membrane within such a large complex. With similar supportive logic and assuming multiple copies of CFTR per complex and likely multiple complexes within each vesicle as cargo, a $\triangle F$-CFTR copy would attract chaperones that would identify the folding defect and attempt to retain this misfolded $\triangle$ F-CFTR protein and associated proteins. More than one $\Delta$ F-CFTR protein copy would amplify such attempted ER retention. If copies of WT-CFTR are also present within this large complex, they would be retained, snared or 'caught up in' this delF-CFTR retention in other parts of the large complex. Finally, we believe that this dominant negative effect would occur ahead of either Golgi-driven trafficking to the plasma membrane or non-traditional GRASP dependent trafficking that do not involve the complex Golgi apparatus [58,59].

There are a number of proteins that are associated with CFTR that could influence a dominant negative inhibition of WT-CFTR by $\triangle$ F-CFTR. Two classes of epithelial-specific accessory proteins likely involved are ER resident chaperones and the PDZ binding proteins. The heat shock family of proteins (HSP) is known to associate with CFTR at the level of the ER as a key group of CFTR chaperones. All members of this family have ATPase activity that is directly linked to their ability to associate/disassociate with their protein substrate. Potential candidates include HSP90, HSP70 and its cognate HSC70 in conjunction with HSP40 and CHIP [60-67]. Recently, Balch and coworkers identified a 'chaperone trap' for CFTR that included HSP40, HSP70 and HSP90 [67]. The latter HSP is known to interact with both WTCFTR and $\triangle$ F-CFTR and exists in a dimeric state. A CFTR dimer could conceivably form through an HSP90 dimer at least transiently during CFTR biogenesis in the ER. HSP70 is a less studied protein in CF; however, it does bind CFTR. Its cognate relative, HSC70, is better understood. HSC70 mediates CFTR degradation in the ER through its interaction with HSP40 and CHIP [64]. HSC70's association with CFTR and other protein substrates is regulated by its fellow chaperone, Hdj-2, an HSP40 family member [64]. In addition, CHIP, as a cochaperone, binds the HSC70/Hdj-2 complex via one of three tetratricopeptide repeat (TRP) domains. This interaction inhibits the ATPase activity induced by $\mathrm{Hdj}-2$ on HSC 70 and prolongs the interaction of CHIP with HSC70 and with the nascent CFTR peptide. Moreover, CHIP has 3 TRP domains and could bind at least 3 CFTR/HSC70/Hdj-2 complexes [64] and target all to the degradation pathway if one or more of the CFTR polypeptides being processed bore the $\triangle \mathrm{F}$-CFTR.

The second class of proteins likely involved in the dominant negative interaction are the PDZ binding domain family of proteins that have the class 1 PDZ domains which recognizes the QDTRL sequence in the end of the CFTR $C$ terminus. Candidates include CAL, EBP50/NHERF-1, E3KARP, and CAP70 that likely influence both trafficking and anchoring of membrane proteins like CFTR and that may be more deeply involved in the ER processing than described previously [35-41,53]. CAL or CFTR-associated ligand is a Golgi resident PDZ protein which can prevent CFTR from reaching the plasma membrane. CAL has only one PDZ domain but exist in a homomultimeric state and could tether multiple CFTR polypeptides together. EBP-50, ezrin-binding protein 50 or $\mathrm{Na} / \mathrm{H}$ exchange regulatory factor 1 (NHERF-1) has two PDZ binding domains which could, in theory, tether nascent $\triangle \mathrm{F}$-CFTR and WT-CFTR polypeptides together if co-expressed in the ER. CAP70, CFTR-associating protein 70 , has 4 PDZ domains and 3 of those domains bind CFTR with significant affinity in the order, $3>1>4$. This protein could also bind up to three CFTR molecules and transport 
them to the cell surface or divert the three "tethered" proteins to the degradation pathway if one or two of the three CFTR polypeptides possessed the $\triangle \mathrm{F}$-CFTR mutation. We hypothesize that chaperones, co-chaperones, and PDZ binding proteins resident in the ER may all play a significant role in the $\triangle$ F-CFTR/WT-CFTR inhibitory interaction during processing in airway epithelia.

Our finding and the associated CFTR biology in native epithelial cells has profound implications regarding the development of efficient therapeutic methods to correct or replace $\triangle \mathrm{F}$-CFTR in vivo. Although the understanding of CFTR biology has advanced significantly in recent years, there is much still poorly understood regarding the processing and function of CFTR in native epithelial cells. A primary and fundamental problem which still exists in the field is a lack in the understanding of how epithelial CFTR is processed, what the exact nature of CFTR's stoichiometry is, and what epithelial accessory proteins interact with epithelial CFTR in the ER, in the Golgi and other organelles, and at the plasma membrane. The discovery and development of CF corrector drugs such as Vertex's VX-809 being examined in CF clinical trials currently is also influenced by this biology and the concept of a $\triangle \mathrm{F}$-CFTR dominant negative inhibition of WT-CFTR when expressed together within an epithelial cell $[55,56]$. An uncorrected $\triangle$ F-CFTR could conceivably still inhibit a corrected $\triangle \mathrm{F}-\mathrm{CFTR}$ in a similar dominant negative manner.

There was a premise within the CF research community that only $10 \%$ of cells along the CF airway or a $10 \%$ correction of $\triangle F-C F T R$ within a given CF cell would be sufficient for a successful therapy. A 10-20\% level of correction was achieved with VX-809 in a recent published study [55]. However, VX-809 itself does not appear potent or effective enough as a single drug in recent clinical trials; it was disappointing by itself in a combination trial with the CFTR potentiator drug, VX-770 (ivacaftor, Kalydeco $^{\mathrm{TM}}$ ) in $\triangle \mathrm{F}$-CFTR homozygous patients. It is now felt that a $50 \%$ level of correction is a better benchmark that is equivalent to $27^{\circ} \mathrm{C}$ reduced temperature correction in a biochemical correction assay. This also approaches the CF heterozygous condition where a carrier would have $50 \%$ of the functional CFTR than a normal or WT individual. This level may need to be the new benchmark for a $\triangle$ F-CFTR correction therapy. While many members in the CF field have been resistant to the concept that the CF heterozygote may harbor dysfunction since $\mathrm{CF}$ heterozygotes do not display a fully developed CF disease phenotype, correction of a $\Delta \mathrm{F}$ CFTR bearing homozygote to a $\triangle \mathrm{F}$-CFTR bearing heterozygote would control CF disease. Our work also suggests that more research should be done addressing both the CF patient and the heterozygotic CF carrier in contrast to the normal or non-CF WT controls. One suggestion from these studies is that WT mice, CF heterozygous mice, and CF homozygous mice, especially within $\triangle$ F-CFTR mouse models, should be studied as three separate experimental groups in the future. In particular, these three experimental groups may be informative to the study of CFTR biology and its influence on other epithelial cell functions.

\section{Conclusions}

Taken together, $\triangle$ F-CFTR inhibition of WT-CFTR during protein processing in the ER of native CF human bronchial epithelial cells explains CF-like disease symptoms but not fully developed CF disease in CF heterozygous carriers, the majority of whom are $\mathrm{WT} / \Delta \mathrm{F}$ carriers in the overall population. Attainment of CF heterozygote level of function with CF corrector drugs and other strategies would also serve as a critical benchmark for CF therapy in the near future. Finally, we propose that both ER-resident chaperones and PDZ-binding proteins likely play critical roles in CFTR-driven multimeric, oligomeric and/or macromolecular complex formation that provide a suitable environment for $\triangle \mathrm{F}$-CFTR dominant negative inhibition of WT-CFTR processing and, thus, trafficking and function.

\section{Competing interests}

These studies were purely basic science in nature. There are no competing or non-competing financial interests related to this work.

\section{Animal ethics}

Studies involving animals were performed with UAB CF Center Cores that had and still holds appropriate and approved animal protocols.

\section{Authors' contributions}

All authors warrant authorship as outlined by BioMedCentral guidelines. TAT was the main driver of this study and made the initial observation of a dominant negative-like effect of delF508-CFTR on wild-type CFTR expression and function when optimizing lipid-based transient transfection methods on polarized and non-polarized airway and other epithelial cell cultures. This study was highly controversial several years ago when it was performed because of the debates over CFTR monomer versus multimer, over disease phenotypes in CF heterozygotes, over differences in CFTR protein processing in epithelial versus heterologous cells, etc. It remains so. AZ assisted TAT on the SPQ and Ussing chamber functional assays. JAF assisted TAT, AZ and EMS on the NPD recordings in the two different CF mouse models on behalf of the UAB CF Center. MD, LF and DMB assisted the program in CF mouse strain breeding and husbandry. EMS and LMS are collaborators and were involved in supervision of the overall study. All authors read and approved the final manuscript.

\section{Acknowledgments}

We thank the Department of Cell Developmental and Integrative Biology for infrastructure support in the accomplishment of this important study. In particular, we thank Drs. Karoly Varga, Zsuzsanna Bebok and Jim Collawn for advice about biochemical methods of CFTR detection. We also thank the Gregory Fleming James Cystic Fibrosis Center and its Transgenic Mouse, Ussing Chamber Electrophysiology and Nasal Potential Difference

Measurement Cores within the Center's Research Development Center and its P30 Translational and Research Core Centers for the collective support. Multiple NIH grants from the NIDDK and NHLBI for EMS, LMS, and DMB are also cited for critical support for this study.

We also thank the Gregory Fleming James Cystic Fibrosis Center and its Transgenic Mouse, Ussing Chamber Electrophysiology and Nasal Potential Difference Measurement Cores within the Center's Research Development 
Center and its P30 Translational and Research Core Centers for the collective support. In particular, we thank Drs. Ming Du and David M. Bedwell and the Transgenic Mouse Core for extensive animal husbandry for the numerous nasal PD measurements made for this study. Multiple past $\mathrm{NIH}$ grants from the NIDDK and NHLBI for EMS and LMS are also cited for critical support for this study.

\section{Author details}

'Departments of Cell Developmental and Integrative Biology, University of Alabama at Birmingham, 1918 University Blvd, Birmingham, AL 35294-0005, USA. ${ }^{2}$ Gregory Fleming James Cystic Fibrosis (CF) Research Center, University of Alabama at Birmingham, 1918 University Blvd, Birmingham 35294-0005AL, USA. ${ }^{3}$ Department of Experimental Human Physiology, Semmelweis University, Budapest, Hungary. ${ }^{4}$ Department of Biochemistry, University of Texas Health Sciences Center at Tyler, Tyler, TX, USA. ${ }^{5}$ DiscoveryBioMed, Inc, Birmingham, AL, USA.

Received: 11 March 2012 Accepted: 4 September 2012

Published: 24 September 2012

\section{References}

1. Riordan JR, Rommens JM, Kerem B, Alon N, Rozmahel R, Grzelczak Z, Zielenski J, Lok S, Plavsic N, Chou JL, et al: Identification of the cystic fibrosis gene: cloning and characterization of complementary DNA. Science 1989, 245:1066-1073.

2. Rommens JM, lannuzzi MC, Kerem B, Drumm ML, Melmer G, Dean M, Rozmahel R, Cole JL, Kennedy D, Hidaka N, et al: Identification of the cystic fibrosis gene: chromosome walking and jumping. Science 1989, 245:1059-1065.

3. Kerem B, Rommens JM, Buchanan JA, Markiewicz D, Cox TK, Chakravarti A, Buchwald M, Tsui LC: Identification of the cystic fibrosis gene: genetic analysis. Science 1989, 245:1073-1080

4. Schwiebert EM, Benos DJ, Egan ME, Stutts MJ, Guggino WB: CFTR is a conductance regulator as well as a chloride channel. Phys Rev 1999, 79:S145-S166.

5. Lukacs GL, Verkman AS: CFTR: Folding, misfolding, and correcting the deltaF508 conformational defect. Trends Mol Med 2012, 18(2):81-91.

6. Guggino WB, Stanton BA: New insights into cystic fibrosis: Molecular switches that regulate CFTR. Nat Rev Mol Cell Biol 2006, 7(6):426-436.

7. Salvatore F, Scudiero O, Castaldo G: Genotype-phenotype correlation in cystic fibrosis: the role of modifier genes. Am J Med Genet 2002 111:88-95.

8. Rowntree RK, Harris A: The phenotypic consequences of CFTR mutations. Ann Hum Genet 2003, 67:471-485.

9. Oceandy D, McMorran BJ, Smith SN, Schreiber R, Kunzelmann K, Alton EWFW, Hume DA, Wainwright BJ: Gene complementation of airway epithelium in the cystic fibrosis mouse is necessary and sufficient to correct the pathogen clearance and inflammatory abnormalities. Human Mol Genet 2002, 11(9):1059-1067.

10. Driskell RA, Engelhardt JF: Current status of gene therapy for inherited lung diseases. Annu Rev Physiol 2003, 65:585-612.

11. Stoltz DA, et al: Cystic fibrosis pigs develop lung disease and exhibit defective bacterial eradication at birth. Sci Transl Med 2010, 2(29):29-31.

12. Sun $X$, et al: Disease phenotype of a ferret CFTR-knockout model of cystic fibrosis. J Clin Invest 2011, 120(9):3149-3160

13. Keiser NW, Engelhardt JF: New animal models of cystic fibrosis: What are they teaching us? Curr Opin Pulm Med 2011, 17(6):478-483.

14. Tucker TA, Varga K, Bebok Z, Zsembery A, McCarty NA, Collawn JF, Schwiebert EM, Schwiebert LM: Transient transfection of polarized epithelial monolayers with CFTR and reporter genes using efficacious lipids. Am J Physiol Cell Physiol 2003, 284:C791-C804.

15. Varga K, Jurkuvenaite A, Wakefield J, Hong JS, Guimbellot JS, Venglarik CJ, Niraj A, Mazur M, Sorscher EJ, Collawn JF, Bebok Z: Efficient intracellular processing of the endogenous cystic fibrosis transmembrane conductance regulator in epithelial cell lines. J Biol Chem 2004, 279:22578-22584.

16. Behm JK, Hagiwara G, Lewiston NJ, Quinton PM, Wine JJ: Hyposecretion of beta-adrenergically induced sweating in cystic fibrosis heterozygotes. Pediatr Res 1987, 22:271-276.

17. Davis PB: Physiologic implications of the autonomic aberrations in cystic fibrosis. Horm Metab Res 1986, 18:217-220.
18. Dahl M, Tybjaerg-Hansen A, Lange P, Nordestgaard BG: DeltaF508 heterozygosity in cystic fibrosis and susceptibility to asthma. Lancet 1998, 351:1911-1913.

19. Miller PW, Hamosh A, Macek M Jr, Greenberger PA, MacLean J, Walden SM, Slavin RG, Cutting GR: Cystic fibrosis transmembrane conductance regulator (CFTR) gene mutations in allergic bronchopulmonary aspergillosis. Am J Hum Genet 1996, 59:45-51.

20. Coste A, Girodon E, Louis S, Pruliere-Escabasse V, Goossens M, Peynegre R, Escudier E: Atypical sinusitis in adults must lead to looking for cystic fibrosis and primary ciliary dyskinesia. Laryngoscope 2004, 114:839-843.

21. Steagall WK, Elmer HL, Brady KG, Kelley TJ: Cystic fibrosis transmembrane conductance regulator-dependent regulation of epithelial inducible nitric oxide synthase expression. Am J Respir Cell Mol Biol 2000, 22:45-50.

22. Bear CE LIC, Kartner N, Bridges RJ, Jensen TJ, Ramjeesingh M, Riordan JR: Cl channel activity in Xenopus oocytes expressing the cystic fibrosis gene. Cell 1992, 68:809-818.

23. Li C, Roy K, Dandridge K, Naren AP: Molecular assembly of cystic fibrosis transmembrane conductance regulator in plasma membrane. J Biol Chem 2004, 279:24673-24684.

24. Ramjeesingh M, Ugwu F, Li C, Dhani S, Huan LJ, Wang Y, Bear CE: Dimeric cystic fibrosis transmembrane conductance regulator exists in the plasma membrane. Biochem J 2003, 375:633-641.

25. Chen JH, Chang XB, Aleksandrov AA, Riordan JR: CFTR is a monomer: biochemical and functional evidence. J Membr Biol 2002, 188:55-71.

26. Eskandari S, Wright EM, Kreman M, Starace DM, Zampighi GA: Structural analysis of cloned plasma membrane proteins by freeze-fracture electron microscopy. Proc Natl Acad Sci USA 1998, 95:11235-11240.

27. Zerhusen B, Zhao J, Xie J, Davis PB, Ma J: A single conductance pore for chloride ions formed by two cystic fibrosis transmembrane conductance regulator molecules. J Biol Chem 1999, 274:7627-7630.

28. Boscoboinik D, Debanne MT, Stafford AR, Jung CY, Gupta RS, Epand RM: Dimerization of the P-glycoprotein in membranes. Biochim Biophys Acta 1990, 1027:225-228.

29. Wang S, Yue H, Derin RB, Guggino WB, Li M: Accessory protein facilitated CFTR-CFTR interaction, a molecular mechanism to potentiate the chloride channel activity. Cell 2000, 103:169-179.

30. Raghuram V, Mak DD, Foskett JK: Regulation of cystic fibrosis transmembrane conductance regulator single-channel gating by bivalent PDZ-domainmediated interaction. Proc Natl Acad Sci USA 2001, 98:1300-1305.

31. Lukacs GL, Chang XB, Bear C, Kartner N, Mohamed A, Riordan JR, Grinstein S: The delta F508 mutation decreases the stability of cystic fibrosis transmembrane conductance regulator in the plasma membrane. Determination of functional half-lives on transfected cells. $J$ Biol Chem 1993, 268:1592-1598.

32. Clarke LL, Gawenis LR, Hwang TC, Walker NM, Gruis DB, Price EM: A domain mimic increases DeltaF508 CFTR trafficking and restores CAMPstimulated anion secretion in cystic fibrosis epithelia. Am J Physiol Cell Physiol 2004, 287:C192-C199.

33. Cormet-Boyaka E, Jablonsky M, Naren AP, Jackson PL, Muccio DD, Kirk KL: Rescuing cystic fibrosis transmembrane conductance regulator (CFTR) processing mutants by transcomplementation. Proc Natl Acad Sci USA 2004, 101:8221-8226.

34. Heda GD, Tanwani M, Marino CR: The Delta F508 mutation shortens the biochemical half-life of plasma membrane CFTR in polarized epithelial cells. Am J Physiol Cell Physiol 2001, 280:C166-C174.

35. He J, Bellini M, Xu J, Castleberry AM, Hall RA: Interaction with CAL inhibits beta-1-adrenergic receptor surface expression. J Biol Chem 2004, 279:50190-50196

36. Cheng J, Moyer BD, Milewski M, Loffing J, Ikeda M, Mickle JE, Cutting GR, Li M, Stanton BA, Guggino WB: A Golgi-associated PDZ domain protein modulates cystic fibrosis transmembrane regulator plasma membrane expression. J Biol Chem 2002, 277:3520-3529.

37. Swiatecka-Urban A, Duhaime M, Coutermarsh B, Karlson KH, Collawn J, Milewski M, Cutting GR, Guggino WB, Langford G, Stanton BA: PDZ domain interaction controls the endocytic recycling of the cystic fibrosis transmembrane conductance regulator. J Biol Chem 2002, 277:40099-40105.

38. Cheng J, Cebotaru V, Cebotaru L, Guggino WB: Syntaxin 6 and CAL mediate the degradation of the CFTR. Mol Biol Cell 2010, 21(7):1178-1187.

39. Cushing PR, Fellows A, Villone D, Boisguerin P, Madden DR: The relative binding affinities of PDZ partners for CFTR: a biochemical basis for efficient endocytic recycling. Biochemistry 2008, 47(38):10084-10098. 
40. Tandon C, De Lisle RC, Boulatnikov I, Naik PK: Interaction of carboxylterminal peptides of cystolic-tail of apactin with PDZ domains of NHERF/ EBP50 and PDZK-1/CAP70. Mol Cell Biochem 2007, 302(1-2):157-167.

41. Lee JH, Richter W, Namkung W, Kim KH, Kim E, Conti M, Lee MG: Dynamic regulation of cystic fibrosis transmembrane conductance regulator by competitive interactions of molecular adaptors. J Biol Chem 2007, 282(14):10414-10422.

42. Cuthbert AW, MacVinish L: Mechanisms of anion secretion in Calu-3 human airway epithelial cells by 7,8-benzoquinoline. Br J Pharmacol 2003, 140:81-90.

43. Xiao YF, Wright SN, Wang GK, Morgan JP, Leaf A: Fatty acids suppress voltage-gated $\mathrm{Na}^{+}$currents in HEK293t cells transfected with the alphasubunit of the human cardiac $\mathrm{Na}^{+}$channel. Proc Natl Acad Sci USA 1998, 95:2680-2685

44. Ward CL, Kopito RR: Intracellular turnover of cystic fibrosis transmembrane conductance regulator. Inefficient processing and rapid degradation of wild-type and mutant proteins. J Biol Chem 1994, 269:25710-25718

45. Jensen TJ, Loo MA, Pind S, Williams DB, Goldberg AL, Riordan JR: Multiple proteolytic systems, including the proteasome, contribute to CFTR processing. Cell 1995, 83:129-135.

46. Li H, Sheppard DN, Hug MJ: Transepithelial electrical measurements with the Ussing chamber. J Cyst Fibros 2004, 2:123-126.

47. Braunstein GM, Zsembery A, Tucker TA, Schwiebert EM: Purinergic signaling underlies CFTR control of human airway epithelial cell volume. J Cyst Fibros 2004, 3:109-117.

48. Zeiher BG, Eichwald E, Zabner J, Smith JJ, Puga AP, McCray PB Jr, Capecchi MR, Welsh MJ, Thomas KR: A mouse model for the delta F508 allele of cystic fibrosis. J Clin Invest 1995, 96:2051-2064

49. Snouwaert JN, Brigman KK, Latour AM, Malouf NN, Boucher RC: An animal model for cystic fibrosis made by gene targeting. Science 1992, 257:1083-1088.

50. Hentchel-Franks K, Lozano D, Eubanks-Tarn V, Cobb B, Fan L, Oster R, Sorscher E, Clancy JP: Activation of airway $\mathrm{Cl}^{-}$secretion in human subjects by adenosine. Am J Respir Cell Mol Biol 2004, 31:140-146.

51. Cobb BR, Ruiz F, King CM, Fortenberry J, Greer H, Kovacs T, Sorscher EJ, Clancy JP: $A(2)$ adenosine receptors regulate CFTR through PKA and PLA (2). Am J Physiol Lung Cell Mol Physiol 2002, 282:L12-L25.

52. Moyer BD, Denton J, Karlson KH, Reynolds D, Wang S, Mickle JE, Milewski M, Cutting GR, Guggino WB, Li M, Stanton BA: A PDZ-interacting domain in CFTR is an apical membrane polarization signal. J Clin Invest 1999, 104(10):1353-1361.

53. Li C, Naren AP: Analysis of CFTR interactome in macromolecular complexes. Methods Mol Biol 2011, 741:255-270.

54. Accurso FJ, et al: Effect of VX-770 in persons with cystic fibrosis and the G551D-CFTR mutation. N Engl J Med 2010, 363(21):1991-2003.

55. Van Goor F, et al: Correction of the delF508-CFTR protein processing defect in vitro by investigational drug VX-809. Proc Natl Acad Sci USA 2011, 108(46):18843-18848.

56. Clancy JP, et al: Results of a Phase lla study of VX-809, an investigational CFTR corrector compound, in subjected with cystic fibrosis homozygous for the delF508-CFTR mutation. Thorax 2010, 67(1):12-18.

57. Schwiebert LM, Rice WC, Kudlow BA, Taylor AL, Schwiebert EM: Extracellular ATP signaling and P2X nucleotide receptors in monolayers of primary human vascular endothelial cells. Am J Physiol Cell Physiol 2002, 282:C289-C301.

58. Gee HY, Noh SH, Tang BL, Kim KH, Lee MG: Rescue of deltaF508-CFTR trafficking via a GRASP-dependent unconventional secretion pathway. Cell 2011, 146(5):746-760.

59. Yoo JS, Moyer BD, Bennykh S, Yoo HM, Riordan JR, Balch WE: Nonconventional trafficking of the cystic fibrosis transmembrane conductance regulator through the early secretory pathway. J Biol Chem 2002, 277(13):11401-11409.

60. Rubenstein RC, Lyons BM: Sodium 4-phenylbutyrate downregulates HSC70 expression by facilitating mRNA degradation. Am J Physiol Lung Cell Mol Physiol 2001, 281:L43-L51.

61. Gebauer M, Zeiner M, Gehring U: Proteins interacting with the molecular chaperone hsp70/hsc70: physical associations and effects on refolding activity. FEBS Lett 1997, 417:109-113.

62. Choo-Kang LR, Zeitlin PL: Induction of HSP70 promotes DeltaF508 CFTR trafficking. Am J Physiol Lung Cell Mol Physiol 2001, 281:L58-L68.
63. Meacham GC, Patterson C, Zhang W, Younger JM, Cyr DM: The Hsc70 co-chaperone CHIP targets immature CFTR for proteasomal degradation. Nat Cell Biol 2001, 3:100-105.

64. Meacham GC, Lu Z, King S, Sorscher E, Tousson A, Cyr DM: The Hdj-2/Hsc70 chaperone pair facilitates early steps in CFTR biogenesis. EMBO J 1999, 18:1492-1505.

65. Loo MA, Jensen TJ, Cui L, Chang XB, Riordan JR: Perturbation of Hsp90 interaction with nascent CFTR prevents its maturation and accelerates its degradation by the proteasome. EMBO J 1998, 17:6879-6887.

66. Wang X, Koulov AV, Kellner WA, Riordan JR, Balch WE: Chemical and biological folding contribute to temperature-sensitive deltaF508-CFTR trafficking. Traffic 2008, 9(11):1878-1893.

67. Coppinger JA, Hutt DM, Razvi A, Koulov AV, Pankow S, Yates JR 3rd, Balch WE: A chaperone trap contributes to the onset of cystic fibrosis. PLOS One 2012, 7(5):e37682. May 31 Epub ahead of print.

doi:10.1186/1472-6793-12-12

Cite this article as: Tucker et al:: The $\triangle$ F508-CFTR mutation inhibits wildtype CFTR processing and function when co-expressed in human airway epithelia and in mouse nasal mucosa. BMC Physiology 2012 12:12.

\section{Submit your next manuscript to BioMed Central and take full advantage of:}

- Convenient online submission

- Thorough peer review

- No space constraints or color figure charges

- Immediate publication on acceptance

- Inclusion in PubMed, CAS, Scopus and Google Scholar

- Research which is freely available for redistribution
C Biomed Central 